\title{
Natural allelic variations of Saccharomyces cerevisiae impact stuck fermentation due to the combined effect of ethanol and temperature; a QTL-mapping study
}

Philippe Marullo $0^{1,2^{*}}$ (D, Pascal Durrens ${ }^{3,4}$, Emilien Peltier ${ }^{1,2}$, Margaux Bernard ${ }^{1,2}$, Chantal Mansour $^{2}$ and Denis Dubourdieu ${ }^{1 \uparrow}$

\begin{abstract}
Background: Fermentation completion is a major prerequisite in many industrial processes involving the bakery yeast Saccharomyces cerevisiae. Stuck fermentations can be due to the combination of many environmental stresses. Among them, high temperature and ethanol content are particularly deleterious especially in bioethanol and red wine production. Although the genetic causes of temperature and/or ethanol tolerance were widely investigated in laboratory conditions, few studies investigated natural genetic variations related to stuck fermentations in high gravity matrixes.

Results: In this study, three QTLs linked to stuck fermentation in winemaking conditions were identified by using a selective genotyping strategy carried out on a backcrossed population. The precision of mapping allows the identification of two causative genes VHS1 and OYE2 characterized by stop-codon insertion. The phenotypic effect of these allelic variations was validated by Reciprocal Hemyzygous Assay in high gravity fermentations (> $240 \mathrm{~g} / \mathrm{L}$ of sugar) carried out at high temperatures $\left(>28^{\circ} \mathrm{C}\right)$. Phenotypes impacted were mostly related to the late stage of alcoholic fermentation during the stationary growth phase of yeast.
\end{abstract}

Conclusions: Our findings illustrate the complex genetic determinism of stuck fermentation and open new avenues for better understanding yeast resistance mechanisms involved in high gravity fermentations.

Keywords: QTL, OYE2, VHS1, Subtelomeric region, Wine yeast, Temperature, Ethanol

\section{Background}

The yeast Saccharomyces cerevisiae presents huge genetic and phenotypic variability that has been recently captured at a large scale level [1]. Beside its worldwide presence in natural habitat, this species is characterized by domesticated strains used in several industrial processes as biofuel, wine, sake, brewery, and bakery [2] Such strains are specifically adapted to transform sugars in ethanol thought the alcoholic fermentation. One common feature of all industrial strains is the ability to

\footnotetext{
*Correspondence: philippe.marullo@u-bordeaux.fr

'Deceased

'University of Bordeaux, ISW, Unité de recherche OEnologie EA 4577, USC 1366 INRA, 33140 Bordeaux INP, Villenave d'Ornon, France

${ }^{2}$ Biolaffort, 33100 Bordeaux, France

Full list of author information is available at the end of the article
}

ensure a complete sugar to ethanol conversion since stuck fermentations cause economical prejudice in industry. Most of the environmental factors affecting stuck fermentation have been widely reviewed and partially depend on the industrial application $[3,4]$. Stuck fermentations may result from the combination of many different stresses including high ethanol content $[5,6]$, low $\mathrm{pH}[6,7]$, presence of toxins [8, 9], oxygen or nitrogen depletion [10], bacterial contaminations [11, 12], and high temperature $[5,6,13]$. Among others, the combination of high ethanol content and high temperature has been reported to be particularly deleterious for yeast physiology $[5,6,14]$. This is the case for many industrial processes where elevated temperature and high ethanol content are met. Therefore, understanding tolerance 
mechanisms of fermenting yeast in high temperature and high gravity matrixes is of particular interest. First, in bioethanol industry where Simultaneous Saccharification and Fermentation (SSF) at high temperature $\left(35-41{ }^{\circ} \mathrm{C}\right)$ are frequently used [15]. Second, in more traditional food related fermentations; and in particular in red winemaking where the floating cap reaches temperatures significantly higher than those of the bulk liquid, $32-37^{\circ} \mathrm{C}[16,17]$.

In order to improve yeast temperature tolerance during alcoholic fermentation, several genetic strategies have been developed such as mutagenesis $[18,19]$, adaptive evolution $[20,21]$ and breeding strategies $[5,6]$ demonstrating that the fermentation completion of high gravity media at elevated temperatures is a complex quantitative trait. Beside these applied researches, the ability to growth at high temperature was investigated in laboratory conditions. Particularly tolerant strains were found in clinical samples [22], tropical fruits [23] or cachaça brews [24]. These strains, able to growth in laboratory media at up to $42{ }^{\circ} \mathrm{C}$, were used for implementing quantitative genetic approaches carried out in standard laboratory media [25]. The genetic basis of High Temperature Growth (HTG) revealed to be particularly complex highlighting the existence of epistatic networks involving multiple genes and their allelic variations [26-29]. However, these studies were mostly carried out in physiological conditions that are far from the industrial reality. Indeed, many stresses (including the temperature) impact the yeast physiology during the stationary growth phase at high ethanol concentration level. In such conditions, the identification of natural genetic variations preventing stuck fermentation were scarcely identified.

In a previous work, we constructed by successive backcrosses a Nearly Isogenic Lineage (NIL) improved for its fermentation performance at $28^{\circ} \mathrm{C}$ [5]. In this lineage, nearly $93 \%$ of the genome is identical to one parental strain showing stuck fermentation at elevated temperature. The remaining $7 \%$ of the genome contains heterozygous genetic regions that prevent stuck fermentation. In the present work, this genetic material was used for carrying out a QTL mapping using a selective genotyping strategy. Three main QTL were identified and two of them were dissected at the gene level leading to the identification of two causative genes encoding the proteins Oye2p and Vhs1p. The third locus mapped was the subtelomeric region of the chromosome XV that could play a role in this complex trait.

\section{Results}

Genetic material and experimental design

Among many others, the temperature is an impacting factor that influences the fermentation completion [30].
In a previous study, we demonstrated that this parameter induced stuck fermentations for many wine industrial starters when they are steadily fermented at $28^{\circ} \mathrm{C}$. In contrast, in the same media, most of them achieved the fermentation when the temperature was maintained at $24{ }^{\circ} \mathrm{C}$. For another group of strains, the temperature change did not affect the fermentation completion. These observations suggested a differential susceptibility to temperature in high gravity medium that was previously defined as thermo-sensitive/tolerant trait [5]. More generally, the phenotypic discrepancy results in an overall resistance to harsh fermentative conditions which constitutes a complex trait depending many genetics and environmental conditions. Among various wine yeast strains, this phenotypic discrepancy is particularly high for the meiotic segregants B-1A and G-4A, which are derived from commercial starters Actiflore BO213 and Zymaflore F10, respectively (Laffort, FRANCE) (Table 1). In a breeding program, the hybrid $\mathrm{H} 4$ was obtained by successive backcrosses using the tolerant strain, $\mathrm{B}-1 \mathrm{~A}$ as the donor and the sensitive strain, G-4A as the recipient strain (see Fig. 1a). These backcrosses were driven by selecting recursively the meiotic segregants showing the best fermentation completion in high gravity synthetic medium fermented at $28^{\circ} \mathrm{C}$ [5]. The resulting hybrid $\mathrm{H} 4$ had a strong genetic similarity ( 93\%) with the recipient background G-4A but also inherited some genetic regions from B-1A conferring a more efficient fermentation (Fig. 1a).

The aim of the present study is to identify the genetic determinisms explaining the phenotypic variance observed in this nearly isogenic population by applying QTL mapping approach. The overall strategy is presented in the Fig. 1(b and c). Initially, the phenotypic segregation of fermentation traits was investigated in 77-segregants of H4. Then, seven extreme individuals leaving the lowest concentration of residual sugars were individually genotyped by Affymetrix ${ }^{\circ}$ Tiling microarray. This selective genotyping step allowed the localization of genomic regions inherited from B-1A that have been introgressed in the G-4A genome during the backcross. Finally, numerous segregants $(\sim 160)$ belonging to two backcrossed hybrids (H4 and H5) were genotyped using Kompetitive Allele Specific PCR markers (KASP ${ }^{\mathrm{mm}}$ ). A linkage analysis identified three QTLs, two them were molecularly dissected by Reciprocal Hemizygous Assay.

\section{Phenotypic characterization of $\mathrm{H} 4$ progeny}

The parental strains (B-1A, G-4A), the hybrid $\mathrm{H} 4$, and 77 H4-meiotic segregants were fermented in a synthetic grape must containing $260 \mathrm{~g} / \mathrm{L}$ of sugar at $28^{\circ} \mathrm{C}$ (see methods). Most of the strains showed stuck fermentation due to the harsh conditions applied. The 
Table 1 Yeast strains used

\begin{tabular}{|c|c|c|c|}
\hline Strain & Background/description & Relevant genotype ${ }^{a}$ & Reference \\
\hline$\overline{G-4 A}$ & Meiotic segregant of Zymaflore F10 & Mat a/Mat alpha; $\mathrm{HO} / \mathrm{HO} ; \mathrm{OYE2}^{G} / \mathrm{OYE2}^{G} ; \mathrm{VHS1}^{G} \mathrm{NHS1}^{G}$ & [5] \\
\hline $\mathrm{B}-1 \mathrm{~A}$ & Meiotic segregant of Actiflore $\mathrm{BO} 213$ & Mat a/Mat alpha; HO/HO; OYE2 $2^{B} / O Y E 2^{B} ; \mathrm{VHSI}^{B} N H S 1^{B}$ & [5] \\
\hline $\mathrm{H} 4$ & 4th-backcross hybrid G-4A X B-1A & Mat a/Mat alpha; HO/HO; OYE2 ${ }^{G} / O Y E 2^{B} ; V_{H S} 1^{G} N H S 1^{B}$ & [5] \\
\hline $\mathrm{H} 4-2 \mathrm{C}$ & H4 Meiotic segregants & Mat a/Mat alpha;HO/HO; OYE2 ${ }^{B} / O Y E 2^{B} ; V_{H S} 1^{B} N H S 1^{B}$ & This study \\
\hline $\mathrm{H} 4-19 \mathrm{~B}$ & H4 Meiotic segregants & Mat a/Mat alpha; HO/HO; OYE2 $2^{B} / O Y E 2^{B} ; V_{H S 1^{B}} N H S 1^{B}$ & This study \\
\hline $\mathrm{H} 5$ & Hybrid H4-2C x H4-19B & Mat a/Mat alpha; HO/HO; OYE2 $2^{B} / O Y E 2^{B} ; \mathrm{VHS} 1^{B} N H S 1^{B}$ & This study \\
\hline H4-OYE2-G & $\mathrm{H} 4$ & Mat a/Mat alpha; HO/HO; OYE2 ${ }^{G} / O Y E 2^{B}: . k a n M X 4 ; V^{\prime} H S 1^{G} N H S 1^{B}$ & This study \\
\hline H4-OYE2-B & $\mathrm{H} 4$ & Mat a/Mat alpha; HO/HO; OYE2 ${ }^{G}:: k a n M X 4 / O Y E 2^{B} ; V H S 1^{G} N H S 1^{B}$ & This study \\
\hline H4-VHS1-G & $\mathrm{H} 4$ & Mat a/Mat alpha; HO/HO; OYE2 ${ }^{G} / O Y E 2^{B}$; VHS1 ${ }^{G} N H S 1^{B}:: k a n M X 4$ & This study \\
\hline H4-VHS1-B & $\mathrm{H} 4$ & Mat a/Mat alpha; HO/HO; OYE2 $2^{G} / O Y E 2^{B} ; V_{H S} 1^{G}: . k a n M X 4 N H S 1^{B}$ & This study \\
\hline Y02873 & BY4741 & Mat a; his $3 \Delta 1$; leu2 $\Delta 0$; met15 $\Delta 0$; ura3 $\Delta 0$; YHR179w::kanMX4 & \\
\hline Y03606 & BY4741 & Mat a; his $3 \Delta 1$; leu2 $\Delta 0$; met15 $\Delta 0$; ura3 $\Delta 0$; YDR247w::kanMX4 & \\
\hline
\end{tabular}

${ }^{a}$ For OYE2 and VHS1 the exponents $G$ and B indicate the allelic variations for the strains $G-4 A$ and $B-1 A$, respectively

overall phenotypic characterization was carried out by measuring eight quantitative traits (Table 2). According to the phenotype, the heritability $h^{2}$ in the $\mathrm{H} 4$ progeny ranged from 2.5 to $86.9 \%$. Kinetic traits in relation with the early part of alcoholic fermentation ( LP, T35, T50) were poorly heritable and are not statistically different within the parental strains. None of these traits were further investigated due to their low heritability. The lack of segregation within the offspring suggests that all the segregants share similar phenotypes in the first part of the fermentation which correspond to the growth phase. This observation has been previously reported for one particularly tolerant segregants of $\mathrm{H} 4$ showing growth parameters very similar to the parental strain G-4A [5]. In contrast, traits linked to the late part of the fermentation (T70, rate 50-70, ethanol produced, $\mathrm{CO}_{2}$ max, Residual Sugars (RS)) had a high variability. This is the case of the Residual Sugars at the end of the alcoholic fermentation (Fig. 2a). For this trait, the parental strains values are 0.1 and $30.3 \mathrm{~g} / \mathrm{L}$ for $\mathrm{B}-1 \mathrm{~A}$ and $\mathrm{G}-4 \mathrm{~A}$, respectively. A complete overview of the trait segregation is given for all the trait investigated (Additional files 1 and 2). The contrasted segregation between early and late fermentation traits indicates that the underlining genetic determinisms would be linked to modification of the physiological state of fermenting strain occurring in the stationary growth phase. Since they are strongly correlated each together (Additional file 3), only two fermentation traits (Residual Sugar and T70) showing the highest heritability were investigated by QTL mapping.

\section{Narrowing introgressed loci by selective genotyping with Affymetrix ${ }^{\circledR}$ tiling microarray}

In order to identify QTLs, a selective genotyping approach was implemented. First, the genomic DNA of the parental strains G-4A and B-1A were hybridized on
Yeast Tiling Microarray (YTM). Using the algorithm SNP Scanner described by Gresham et al. [32]; 18601 and 12848 SNP were detected with respect to the reference genome (Saccharomyces cerevisiae S288C strain, R49.1.1, 2005) for the strains B-1A and G-4A, respectively. Among these SNP, 3397 non-common positions were found defining putative markers between the parental strains (Additional file 4). The correct assignation of these predicted SNP was verified by checking their position with the complete sequence of the parental strains obtained by whole genome sequencing taking as reference the (Saccharomyces cerevisiae S288C strain, (version Apr2011/sacCer3) (Additional file 4). As the algorithm was not able to predict exactly the position of the SNP, a search window was defined with various intervals ranging from 5 to $20 \mathrm{bp}$. More than $80 \%$ of the detected SNP were located at least than 10 bases of the position predicted by YTM. However, only 1204 predicted SNP were correctly assigned meaning that in our experiment the False Discovery Rate of YTM was close to $65 \%$. Nevertheless, the 1204 validated SNP constitutes reliable bi-allelic markers covering the most part of the genome. According to the inheritance of parental strains (B-1A and G-4A), these markers were thereafter named " $B$ " and "G", respectively. The inheritance of this set of markers was investigated in the $\mathrm{H} 4$ segregants. In order to reduce the genotyping cost, only seven $\mathrm{H} 4$ segregants were individually genotyped by YTM. These segregants were selected on the basis of their ability to achieved the most part of the alcoholic fermentation according to their RS values (Fig. 2a). They represent the best decile of the H4-progeny which is sufficient to narrow the main genetic regions containing QTLs [33]. Due to recurrent backcrosses operated, only 192 markers (green ticks) inherited from B-1A were detected in the genome of the seven progenies genotyped. The 


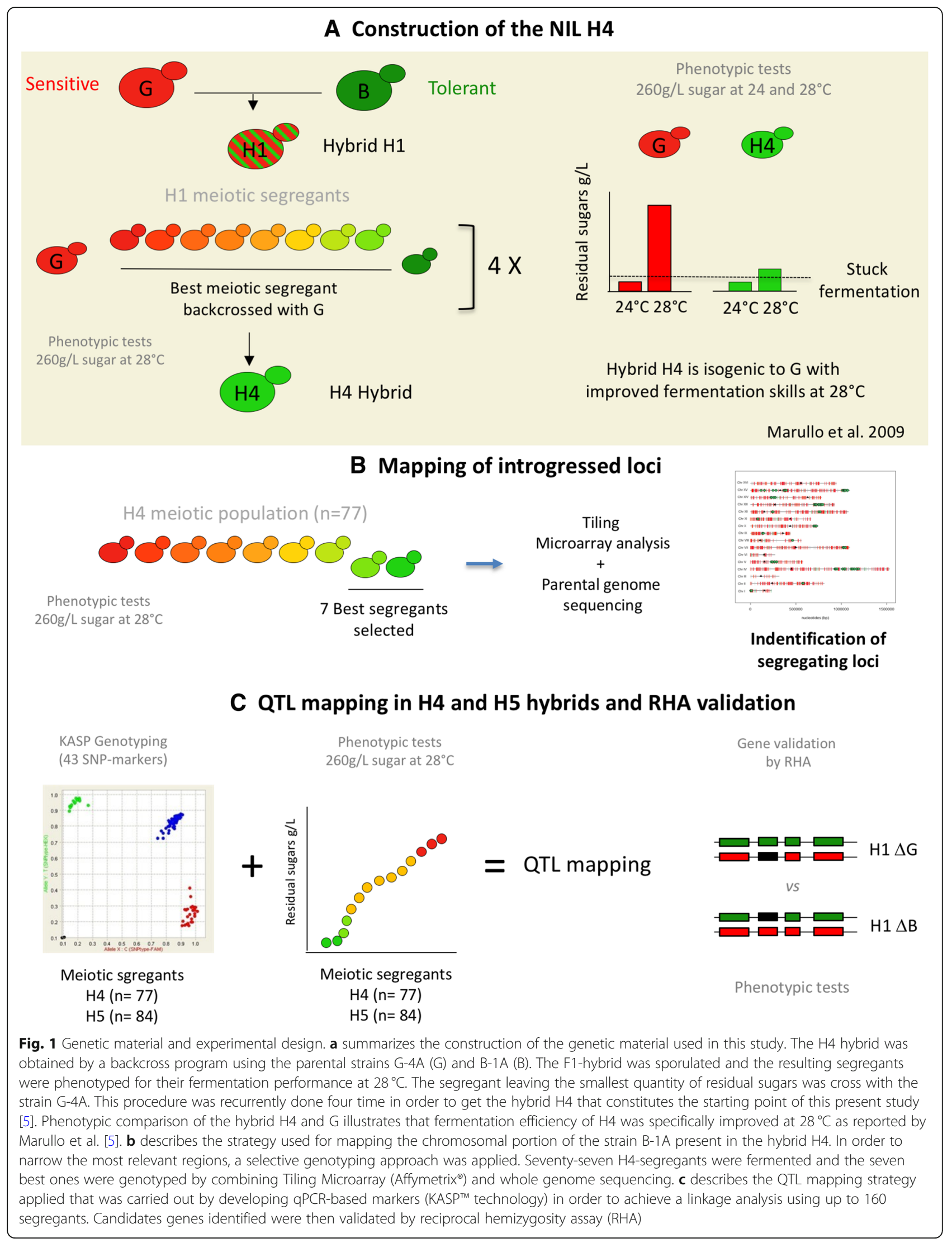


Table 2 Phenotypes of parental strains and for the $\mathrm{H} 4$ progeny

\begin{tabular}{|c|c|c|c|c|c|c|c|c|c|}
\hline \multirow[t]{2}{*}{ Trait } & \multicolumn{2}{|l|}{ G-4A } & \multicolumn{2}{|l|}{$\mathrm{B}-1 \mathrm{~A}$} & \multicolumn{2}{|l|}{$\mathrm{H} 4$} & \multirow{2}{*}{$\begin{array}{l}\text { Parental differences } \\
\text { (Wilcox test } p \text { value) }\end{array}$} & \multicolumn{2}{|c|}{ H4-progeny $(n=77)^{\mathrm{a}}$} \\
\hline & mean & $\overline{\mathrm{SE}}(n=4)$ & mean & $\overline{\mathrm{SE}}(n=4)$ & mean & $\overline{\mathrm{SE}}(n=4)$ & & range & $h^{2}$ \\
\hline CO2max $\left(g . L^{-1}\right)$ & 95.9 & 1.6 & 118.2 & 0.8 & 108.3 & 1.2 & $9.5 \mathrm{E}-06$ & $93.8-117.45$ & 69.6 \\
\hline LP (h) & 4.0 & 1.0 & 4.0 & 0.0 & 3.9 & 0.5 & ns & $3.0-6.5$ & $<5$ \\
\hline T35 (h) & 43.6 & 2.1 & 55.5 & 8.5 & 47.1 & 2.1 & ns & $54.0-92.0$ & $<5$ \\
\hline T50 (h) & 70.8 & 3.7 & 75.5 & 4.5 & 73.0 & 3.2 & ns & $34.0-47.6$ & $<5$ \\
\hline $\mathrm{T} 70$ (h) & 147.2 & 3.8 & 106.5 & 2.5 & 126.0 & 2.8 & $2.0 \mathrm{E}-4$ & $92.3-173.5$ & 86.9 \\
\hline rate $50-70\left(\mathrm{~g} \cdot \mathrm{L}^{-1} \cdot \mathrm{h}^{-1}\right)$ & 0.23 & 0.02 & 0.49 & 0.03 & 0.22 & 0.02 & $1.0 \mathrm{E}-4$ & $0.20-0.53$ & 51.1 \\
\hline RS (g. $\left.L^{-1}\right)$ (Residual Sugars) & 30.3 & 3.18 & 0.1 & 0.03 & 17.29 & 0.9 & $6.0 \mathrm{E}-4$ & $3.5-51.5$ & 79.4 \\
\hline Ethanol (\%Vol) & 12.1 & 0.17 & 14.3 & 0.12 & 13.98 & 0.15 & $6.0 \mathrm{E}-4$ & $11.8-14.7$ & 77.5 \\
\hline
\end{tabular}

${ }^{\mathrm{a}}$ Fermentations were done in duplicate

SE stands for standard error computed for four replicates, ns stands for no significative, $\mathrm{h}^{2}$ stands for heritability and was calculated according to Marullo et al. [31]

remaining 1012-markers were inherited from the parental strain G-4A (red ticks). The B-specific markers were mainly clustered in 12 genomic regions localized in 11 chromosomes (Fig. 2b). Half of them (89 green dots) were found in more than 4 of the 7 progenies genotyped. Since they are more frequently found in the best progenies, those regions are supposed to encompass the B-specific markers allowing a more complete fermentation. According to the segregant, the proportion of B-markers was very similar, ranging between 14.3 and $16.9 \%$. This ratio is a bit higher than expected for a 4 times backcrossed hybrid but clearly confirms that the genetic imprinting of parent B-
1A has been reduced by the backcross procedure as previously demonstrated by a microsatellite analysis [5]. From the 192 B-markers identified, we selected a subset of positions in order to genotype a larger population. On the basis of parental genome sequence, $43 \mathrm{KASP}^{\mathrm{rm}}$ markers localized in the 12 genomic regions were designed (Fig. 2b); their genomic positions are given in (Additional file 5).

\section{Sequential QTL mapping in two NIL populations identifies three loci linked to stuck fermentation}

The 77 segregants of the backcross hybrid $\mathrm{H} 4$ were genotyped by using the KASP ${ }^{\text {ma }}$ markers (LGC genomic
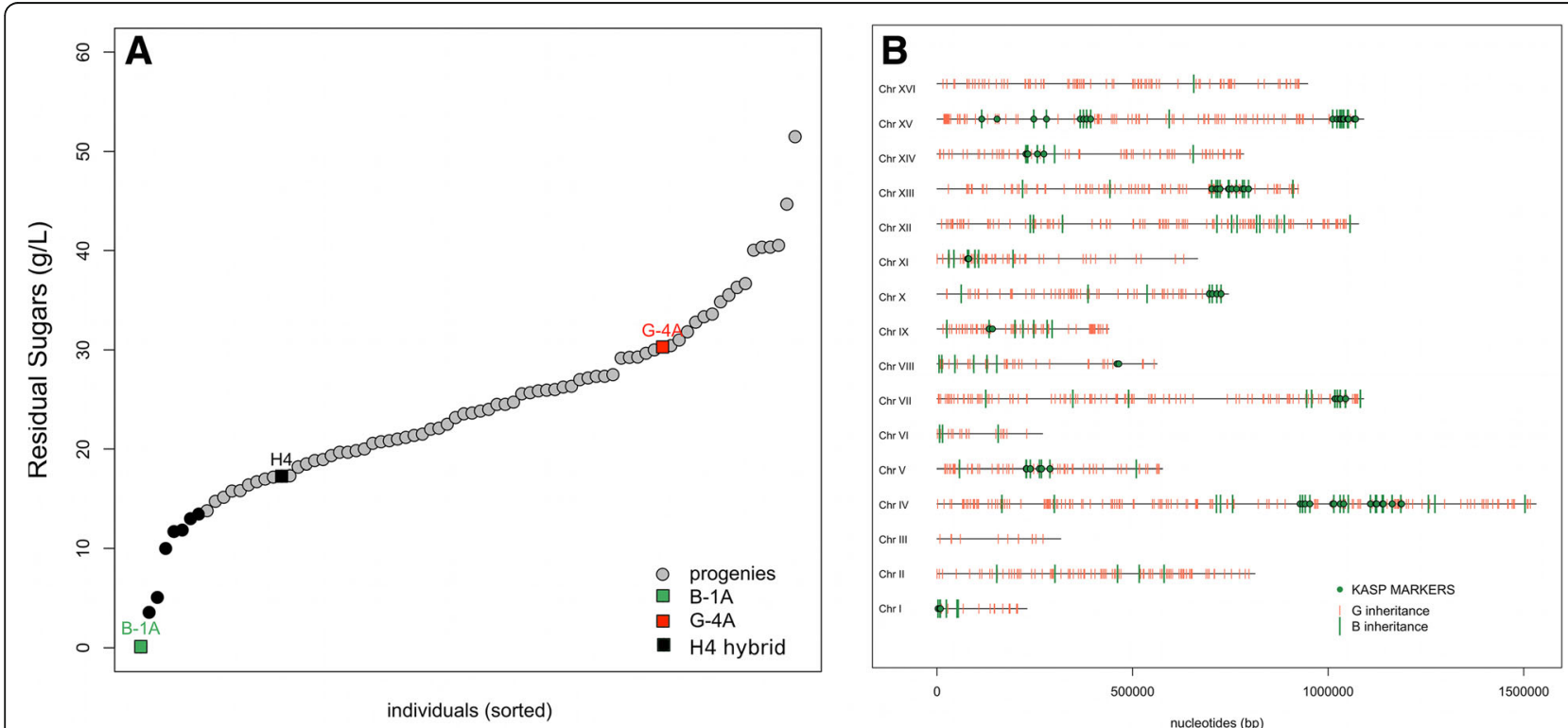

Fig. 2 QTL regions narrowed by selective genotyping. a. Distribution of the residual sugars found at the end of the alcoholic fermentation for the 77 H4-segregants and for the parental strains. The average values of parental strains and H4-hybrid were indicated by green (B-1A), red (G-4A) and black squares (H4-hybrid). The segregants values are the means of experimental duplicates, the seven best progenies (black dots) were selected for narrowing the QTL regions. b, Physical map of all the B-1A and G-4A specific markers inherited in the seven H4 progenies. Each thick is one of the 1204 bi-allelic markers selected. The B and $\mathrm{G}$ alleles are shown in green and red, respectively. The green dots are the SNP that were found in more than four segregants defining 12 chromosomal regions 
company, UK). This technique allows the detection of SNP inheritance by using a qPCR method with labeled primers [34]. The correct Mendelian segregation of these $43 \mathrm{SNP}$ in this population was confirmed (chi ${ }^{2}$ test, $\alpha=0.05$ ) as well as the homozygous status of each segregant (>99\% of the SNPs). A linkage analysis was carried out by using a non-parametric test (Wilcoxon test, $\alpha=0.05$ ) with a significant threshold fixed by 1000 permutations as previously described [35]. The use of non-parametric test was justified by the heterogeneity of variance of the phenotype investigated. Two main QTLs localized on the chromosome IV and VIII were mapped for phenotypes $R S$ and $T 70$ (Fig. $3 \mathrm{a}$ and $\mathrm{b}$ ). The maximum linkage values were found for the markers IV_953 and VIII_464. For both loci, the B-1A inheritance conferred an improved phenotype, which is in accordance with parental strains phenotypes (Fig. 3c and d). The part of variance explained by those QTLs ranged between 15.6 and $25.8 \%$ according to the trait and the locus (Table 3). The analysis of variance of the linear model described an additive effect without interaction.

This first genetic mapping captures only $40 \%$ of the total variance observed within $\mathrm{H} 4$ progeny suggesting that other QTLs playing a minor role were not yet detected. More complex mapping methods integrating the
QTL position as cofactors failed to detect any other loci (data not shown), likely due to the relatively small number of segregants analyzed and the low density of the map. According to the strategy proposed by Sinha et al. [27], the effect of the two major QTLs was removed by performing an additional cross. We selected two $\mathrm{H} 4$ segregants (H4-19B and $\mathrm{H} 4-2 \mathrm{C}$ ) showing a B-alleles inheritance for the QTLs IV_953 and VIII_464. These clones were selected in order to maximize their phenotypic distance for $R S$ (close to $30 \mathrm{~g} / \mathrm{L}$ ). The resulting hybrid H5 was heterozygous for only 23 loci localized in 8 chromosomal regions (Additional file 5).

A population of 84 segregants of the $\mathrm{H} 5$ hybrid was then isolated, phenotyped and genotyped in the same way than for $\mathrm{H} 4$ segregants. The phenotypic segregation of this population is given in the Table 4. Although the trait heritability was lower than for $\mathrm{H} 4$ progeny, some traits of interest such $R S$ and $T 70$ are clearly inheritable and showed a wide segregation. This lower heritability is likely due to the fact that traits were measured without replicates in order to maximize the number of segregants tested. This choice can be justify by the fact the most important factor affecting QTL-mapping efficiency is the number of individuals rather than the phenotype measurement accuracy [33]. A new linkage analysis allowed the detection of one additional QTL localized in
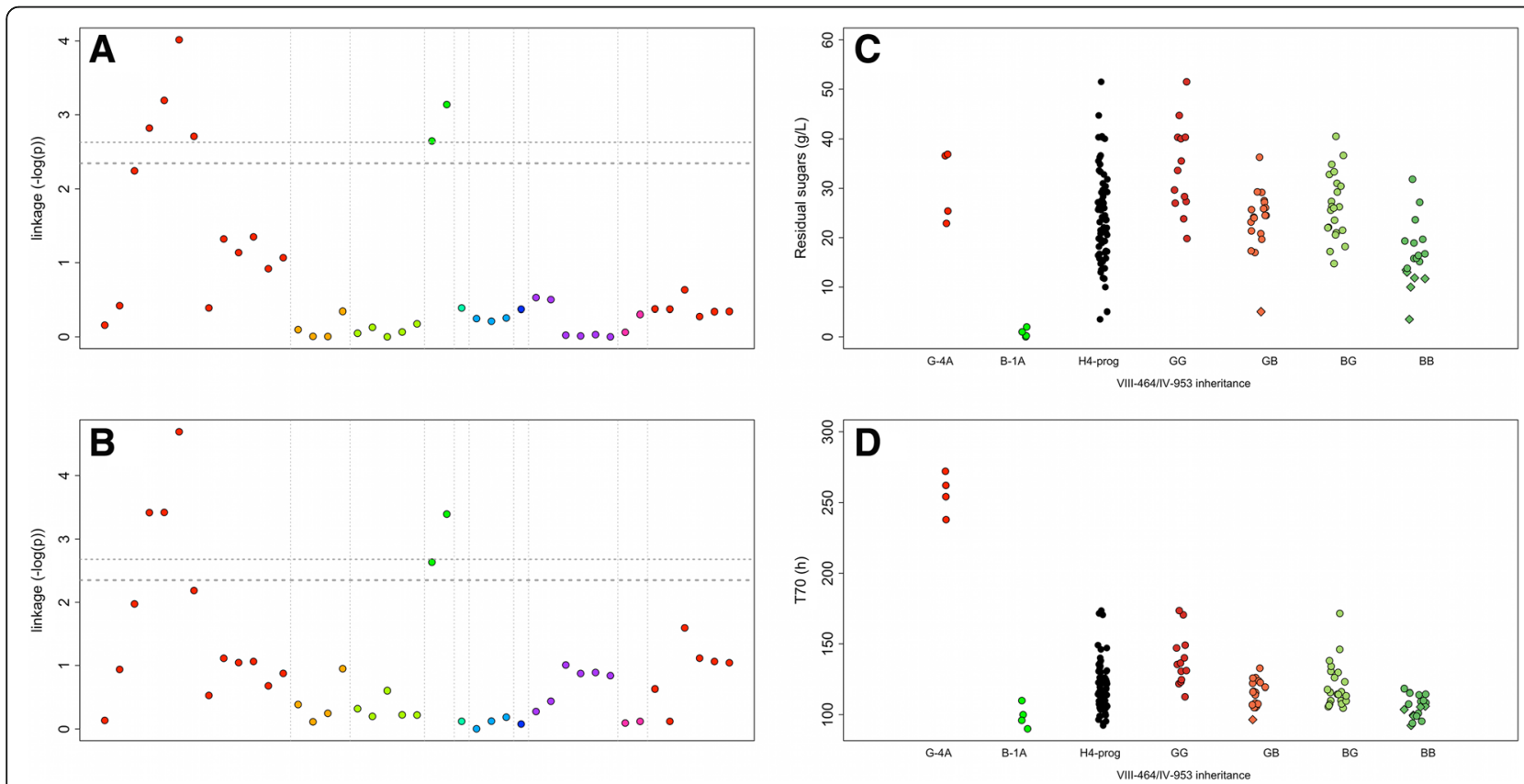

Fig. 3 Linkage analysis in the $\mathrm{H} 4$ progeny. $\mathbf{a}$ and $\mathbf{b}$ show the linkage score expressed in - log of pvalue (Wilcox-Mann-Withney test) for the 43 qPCR markers used for QTL mapping of Residual sugars and T70, respectively. The dot colors represent markers on different chromosomes. The $p$ value thresholds of False discovery Rate (FDR 10 and 5\%) were estimated by permutation tests $(n=1000)$ and are shown by tight and wide dotted lines, respectively. $\mathbf{c}$ and $\mathbf{d}$. Trait distribution among the H4 progeny according to the inheritance at the loci VII-464 and IV-953 for Residual Sugars $(\mathrm{g} / \mathrm{L})$ and $\mathrm{T} 70(\mathrm{~h})$, respectively. The parental values are indicated at the left part of the dot plot. The seven progenies selected were indicated by diamonds symbols. The letters $G$ and B stands for G-4A and B-1A inheritance, respectively 
Table 3 QTL effects and part of variance explained

\begin{tabular}{|c|c|c|c|c|c|}
\hline \multirow[t]{2}{*}{ Locus } & \multirow[t]{2}{*}{$\mathrm{NIL}$} & \multicolumn{2}{|l|}{ T70 } & \multicolumn{2}{|l|}{ RS } \\
\hline & & Part of variance explained (\%) & $P$ value & Part of variance explained (\%) & $P$ value \\
\hline VIII_464 & $\mathrm{H} 4^{\mathrm{a}}$ & 19.8 & $1.30 \mathrm{e}-05$ & 15.6 & $6.03 e-05$ \\
\hline IV_953 & $\mathrm{H} 4^{\mathrm{a}}$ & 17.7 & $3.25 \mathrm{e}-05$ & 25.8 & $6.05 e-07$ \\
\hline VIII_464:IV_953 & $\mathrm{H} 4^{\mathrm{a}}$ & 1.4 & 0.209 & 0.6 & 0.404 \\
\hline$X V \_1051$ & $\mathrm{H} 5^{\mathrm{b}}$ & 7.4 & 0.0152 & 7.7 & 0.008 \\
\hline
\end{tabular}

${ }^{a}$ ANOVA II performed with a classical linear model with interaction, the variables declared are the loci VIII_464, IV_953 with two possible levels B and G according to the genotype

${ }^{\mathrm{b}}$ One way ANOVA, the variable declared is the locus XV_1051 with two possible levels B and G according to the genotype

the subtelomeric region of chromosome XV (Fig. 4a). The maximum peak linkage was found for the marker XV_1051. Surprisingly, for this locus the G-4A allele was linked to a more efficient fermentation for both $R S$ and $T 70$ traits. One-way analysis of variance indicates that only $7.5 \%$ of the total variance was explained by this QTL in the H5 progeny (Table 3).

\section{Impact of the NADPH oxidoreductase Oye2p on stuck} fermentation in high sugars and temperatures conditions We first investigated the QTL VIII_464 by analyzing the genomic sequence of both parental strains neighboring $15 \mathrm{~kb}$ from the best marker found. This region (456000 to $472000 \mathrm{bp}$ ) encompassed 7 genes; four of them (STB5, OYE2, YHR180W, YHR182W) showed non-synonymous SNP between the parental strains (Additional file 6). At less than $2 \mathrm{~kb}$ of the QTL peak, a deletion at the position genomic position 462732 (c.229_230delTC) produced a frame-shift mutation in the OYE2 gene of the parental strain G-4A (p.Ser77fsTer95). The resulting ORF produces a truncated protein of only 95 amino acids instead of the 400 expected in the full-length protein. This two-bases deletion was thereafter named $O Y E 2^{G}$ allele. In contrast, the strain $\mathrm{B}-1 \mathrm{~A}$ has the same sequence than the reference genome (S288c) encoding for a full-length protein form (thereafter named $O Y E 2^{B}$ ). By screening genome databases, we did not detect this specific deletion in other 100 strains (data not shown). However, two other strains carry missense polymorphisms that generate truncated Oye2p proteins OS104 (p.Gly73fs) and S294 (p.Gln176*) (Fig. 5a).

In order to test the impact of this candidate gene, Reciprocal Hemizygous Assay (RHA) [25] was implemented. This method allows the comparison of each parental allele in the H4-hybrid background. The strains H4-OYE2-G and H4-OYE2-B were obtained by using a deletion cassette. These hemizygous hybrids had genotypes $\triangle O Y E 2^{B}:: K a n M x 4 / O Y E 2^{G}$ and $O Y E 2^{B} / \triangle O Y E 2^{G}::$ KanMx4, respectively (Table 1 ). Their fermentation performances were compared at different fermentation temperatures $\left(24,28\right.$ and $32^{\circ} \mathrm{C}$ ). In addition to the $\mathrm{CO}_{2}$ fermentation kinetics, biomass samples were taken in order to estimate the maximal population reached as well as the cell viability at $70 \%$ of the fermentation (Table 5). An analysis of variance (type II) reveals that both temperature and OYE2-allele nature impacted many phenotypes. The temperature effect accounts for the major part of the phenotypic variance confirming its deleterious effect on the fermentation completion in high gravity conditions. Beside this notorious environmental effect, our results demonstrated that the nature of the OYE2 allele significantly affected the fermentation kinetics (T70 and rate), residual sugar content $(R S)$ and the total amount of $\mathrm{CO}_{2}$ produced (Fig. $5 \mathrm{~b}$ and $\mathrm{c}$ ). In contrast, neither growth, biomass content, nor cellular viability were different between the hemizygous hybrids (Additional file 7). Therefore, the physiological impact of Oye $2 p$ concerns more fermentation activity than the cell growth or viability. In standard laboratory conditions,

Table 4 Effect of temperature and OYE2 alleles on the main fermentation parameters

\begin{tabular}{|c|c|c|c|c|c|c|c|c|c|}
\hline \multirow{2}{*}{$\begin{array}{l}\text { Traits } \\
\text { RS }\end{array}$} & \multirow{2}{*}{$\begin{array}{l}\mathrm{H} 4(\Delta / \mathrm{G}) \\
50.6\end{array}$} & \multirow{2}{*}{$\begin{array}{l}\mathrm{H} 4(\mathrm{~B} / \Delta) \\
33.1\end{array}$} & \multicolumn{2}{|c|}{ Allele effect } & \multirow{2}{*}{$\begin{array}{l}24 \\
6.3\end{array}$} & \multirow{2}{*}{$\frac{28}{47.5}$} & \multirow{2}{*}{$\frac{32}{71.6}$} & \multicolumn{2}{|c|}{ Temperature effect } \\
\hline & & & 9.4 & $* * *$ & & & & 88.7 & $* * *$ \\
\hline $\mathrm{CO} 2$ & 98.9 & 104.8 & 5.1 & * & 118.5 & 98.5 & 88.5 & 92.6 & $* * *$ \\
\hline $\mathrm{T} 70$ & 116.5 & 84.5 & 27.8 & $*$ & 91.5 & 85.6 & 124.4 & ns & ns \\
\hline rate & 0.55 & 0.72 & 36.6 & * & 0.69 & 0.68 & 0.52 & ns & ns \\
\hline K & $5.6510^{7}$ & $5.6810^{7}$ & ns & ns & $5.9510^{7}$ & $6.0410^{7}$ & $5.0010^{7}$ & 97.2 & $* * *$ \\
\hline Viability & 52.9 & 63.0 & ns & ns & 73.2 & 69.0 & 32.1 & 87.6 & $* * *$ \\
\hline
\end{tabular}

The hemizygous hybrids carrying the functional alleles $O Y E 2^{B}$ and $\mathrm{OYE}^{G}{ }^{G}$ were respectively encoded $\mathrm{H} 4(\Delta / \mathrm{G})$ and $\mathrm{H} 4(\Delta / \mathrm{B})$. A complete two way ANOVA (type II) model was used for assessing allele, temperature effects and their interactions. Since no significant interactions were detected, only the part of variance explained for allele and temperature treatment were shown. The $p$-value associated is coded as follow, $\mathrm{ns}=p>0.05,{ }^{*}=p<0.05,{ }^{* * *}=p<0.005$ 
Table 5 H5 Phenotypes

\begin{tabular}{|c|c|c|c|c|c|c|c|c|c|}
\hline \multirow[t]{2}{*}{ Trait } & \multicolumn{2}{|c|}{$\mathrm{H} 4-2 \mathrm{C}$} & \multicolumn{2}{|c|}{$\mathrm{H} 4-19 \mathrm{~B}$} & \multirow{2}{*}{$\begin{array}{l}\text { Parental difference } \\
\text { (Wilcoxon test } p \text { value) }\end{array}$} & \multicolumn{4}{|c|}{ H5-progenies $(n=84)^{a}$} \\
\hline & Mean & $\mathrm{SE}(n=5)$ & Mean & $\operatorname{SE}(n=5)$ & & Mean & Variance & Range & $\mathrm{H}$ \\
\hline $\mathrm{CO}_{2} \max \left(g \cdot \mathrm{L}^{-1}\right)$ & 101.7 & 5.2 & 115.0 & 2.6 & ns & 108.8 & 34.6 & $94.6-119.0$ & $<5$ \\
\hline$L P(h)$ & 5.0 & 1.0 & 5.7 & 0.25 & ns & 4.0 & 0.4 & $3-6$ & $<5$ \\
\hline T35 (h) & 34.0 & 1.0 & 36.25 & 2.25 & ns & 34.0 & 1.88 & $31-37$ & $<5$ \\
\hline $\mathrm{T} 50(h)$ & 53.5 & 0.5 & 57.0 & 3.0 & ns & 53.3 & 3.1 & $49-57$ & $<5$ \\
\hline $\mathrm{T} 70$ (h) & 105.0 & 3.0 & 96.5 & 2.5 & 0.08 & 97.1 & 43.7 & $86-117$ & 65.1 \\
\hline rate $50-70\left(\mathrm{~g} \cdot \mathrm{L}^{-1} \cdot \mathrm{h}^{-1}\right)$ & 0.39 & 0.02 & 0.50 & 0.01 & 0.09 & 0.46 & 0.003 & $0.30-0.59$ & 28 \\
\hline RS (g.L L $^{-1}$ ) (Residual Sugars) & 34.19 & 8.9 & 5.49 & 1.95 & 0.06 & 21.00 & 112.13 & $3.34-47.60$ & 29 \\
\hline
\end{tabular}

${ }^{a}$ Fermentations were done without replicate

SE stands for standard error, ns stands for no significative, $\mathrm{h}^{2}$ stands for heritability and was calculated according to Marullo et al. [31]

the OYE2 hemizygous showed exactly the same fitness (data not shown). For the $R S$ measured at $28^{\circ} \mathrm{C}$, the phenotypic difference between H4-OYE2-G and H4OYE2-B hybrids was close to $16 \mathrm{~g} / \mathrm{L}$. By splitting the H4progenies in two groups according to their inheritance for OYE2 marker, the average phenotypic discrepancy within the two groups is only $9.2 \mathrm{~g} / \mathrm{L}$. Epistatic relationships within other genes might explain why the OYE2 effect in H4-offspring is lower than that observed in the hemizygous hybrids. This finding suggests that other genes close to OYE2 might control this phenotype. Nevertheless, our data suggest that the gene OYE2 strongly contributes to the QTL's effect.

As the mutation (p.Ser77fsTer95) is the unique Oye2p peptidic variation found between the parental strains, the OYE2 ${ }^{\mathrm{G}}$ allele (p.Ser77fsTer95) should be responsible of the deleterious effect observed. In the hybrid H4, phenotypes observed are quite similar to those observed in the hemizygous hybrid H4-OYE2-B suggesting the recessive nature of this mutation (Fig. $5 \mathrm{~b}$ and $\mathrm{c}$ ). In other to evaluate more generally the implication of the OYE2 gene in wine fermentations, we assayed in laboratory strain background (BY4741) the physiological impact of its full deletion using the strain $\Delta$ oye2 (Y02873). The fermentation conditions were adapted by reducing the initial sugar content $(180 \mathrm{~g} /$ instead of $260 \mathrm{~g} / \mathrm{L})$ since the laboratory strain is much less adapted than industrial backgrounds (Additional file 8). The OYE2 deletion impacted both kinetics and RS content whatever the temperature of fermentation. These additional results suggest that the OYE2 gene might play a role in fermentation resistance not only at high temperature but also in more permissive conditions.

\section{Impact of the protein kinase Vhs $1 p$ on stuck fermentation in high sugars and temperatures conditions}

The second QTL localized in the right arm of chromosome IV was also investigated. During the backcross procedure, three distinct introgressed regions were inherited form B-1A, encompassing a very large portion of chromosome IV (Fig. 2b). Only the central zone was statistically linked to the phenotype with a maximum peak detected for the marker IV_953. In this genomic region (945500 to 957800), nine non-synonymous variations were found within the parental strains affecting 7 genes (Additional file 6). The most striking mutation
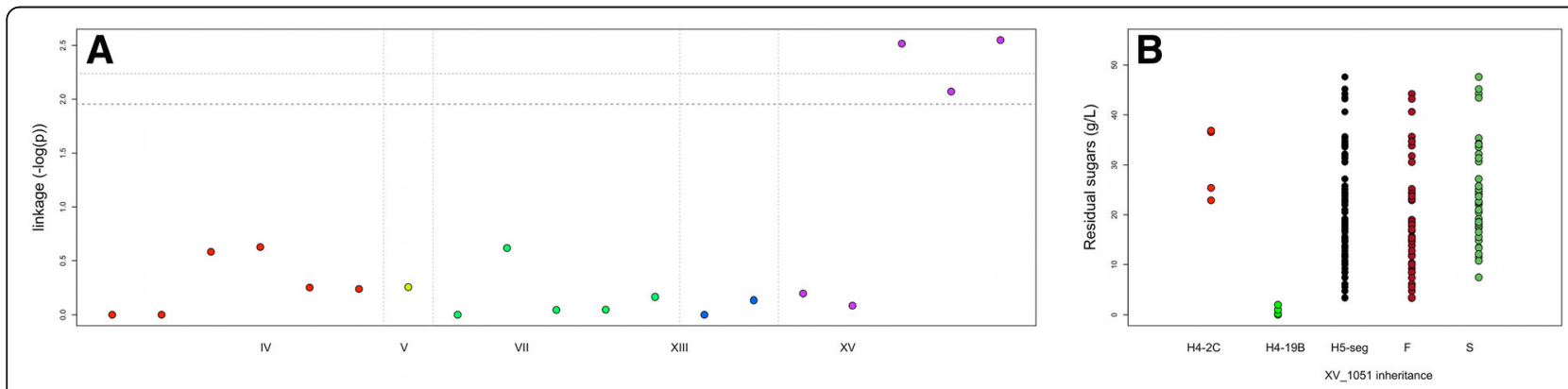

Fig. 4 Mapping of the minor QTL XV in the H5 progeny. a shows the linkage score expressed in - log of p-value (Wilcox-Mann-Withney test) for the 19 gPCR markers used for QTL mapping of Residual sugars in the H5 progeny. The dot colors represent markers on different chromosomes. The p-value threshold of False discovery Rate (FDR 10 and 5\%) was estimated by permutation tests $(n=1000)$ and are shown out by tight and wide dotted lines, respectively. $\mathbf{b}$. Residual Sugars $(\mathrm{g} / \mathrm{L}$ ) distribution among the H5 progeny according to the inheritance at the loci XV_1051. The parental values ( $\mathrm{H} 4-2 \mathrm{C})$ and $\mathrm{H} 4-19 \mathrm{~B}$ ) are indicated at the left part of the dot plot. The letters $\mathrm{G}$ and B stands for $\mathrm{G}-4 \mathrm{~A}$ and B-1A inheritance, respectively 


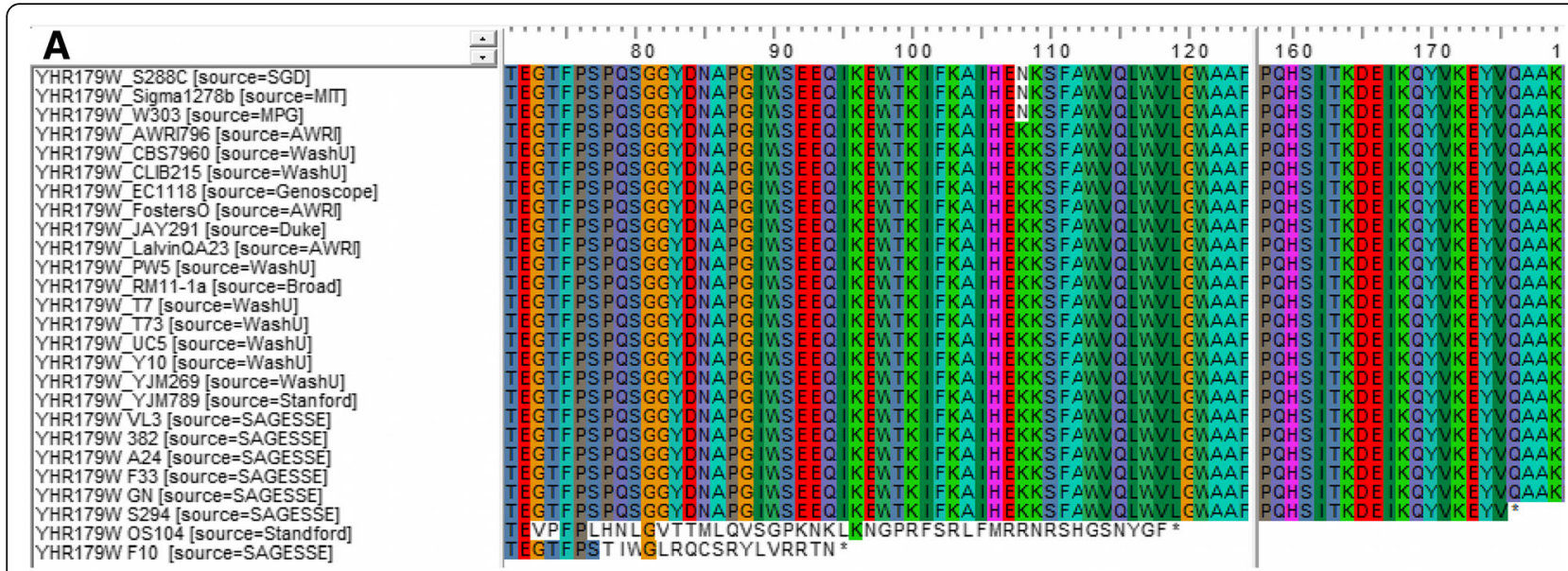
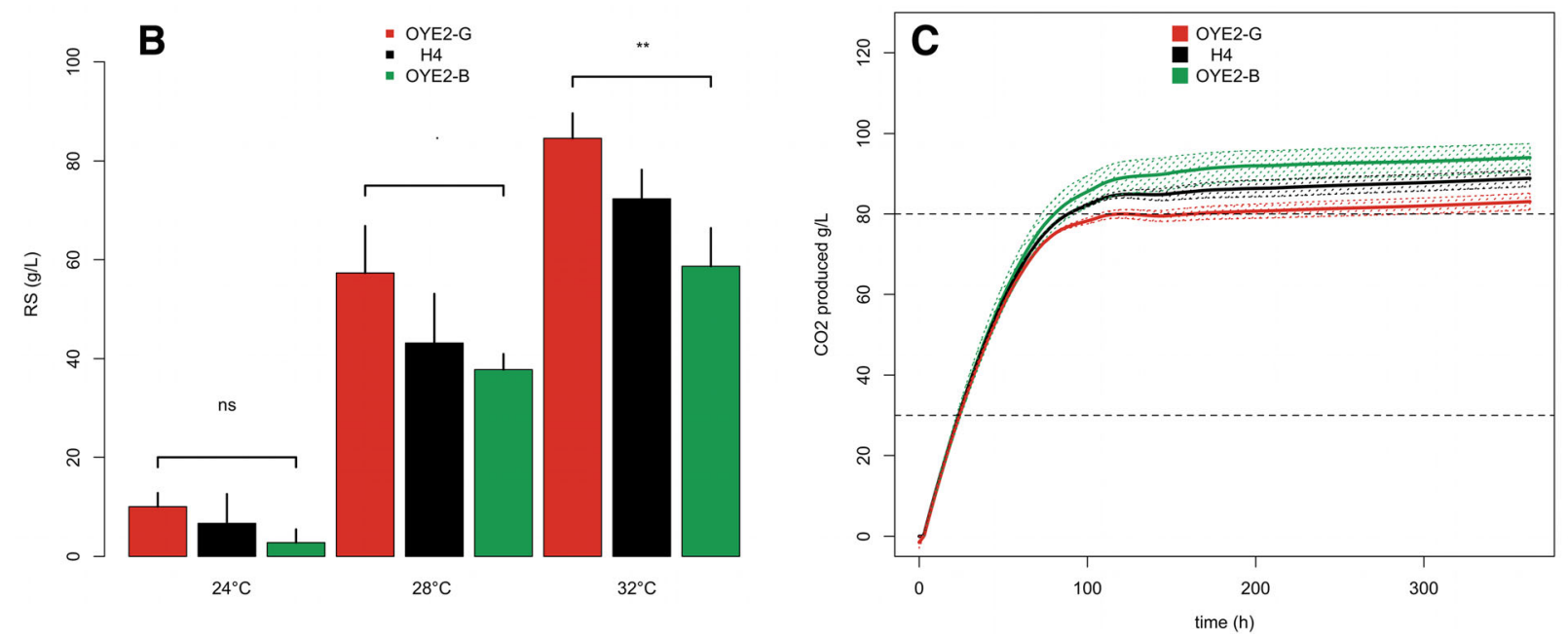

Fig. 5 Physiological effect of the OYE2 alleles. a. Sequence alignments of Saccharomyces cerevisiae Oye2p proteins. The strains F10 (parental strain of G-4A), OS104 and S294 show stop-codon insertion at different positions. $\mathbf{b}$. The bar plots represent the average values of residual sugars after isothermal fermentations carried out at 24,30 and $32^{\circ} \mathrm{C}$ in both hemyzygous hybrids and the native $\mathrm{H} 4$ hybrid. The genotypes $\triangle O Y E 2^{B}:: K a n M \times 4 /$ $\mathrm{OYE2}^{G}, \mathrm{OYE2}^{\mathrm{B}} / \triangle O Y E 2^{G} .: K_{1} M X 4$, and $O Y E 2^{B} / O Y E 2^{G}$ are shown in red, green and black, respectively. Bars represent standard error of five repetitions, the statistical differences between the hemizygous was tested by a Wilcoxon-Mann-Whitney Test (the $p$ value is coded as follow, 'ns' $=p>0.05$, $\because=p<0.1{ }^{* * \prime}=p<0.01$. c. Fermentation kinetics $\left(\mathrm{CO}_{2}\right.$ produced time course) for the same strains and with the same color key

was a nucleotide substitution $\mathrm{C}$ to $\mathrm{A}$ at the position g.957128 producing a stop-codon (p.Tyr372*) in the gene VHS1. This gene encodes for a cytoplasmic serine/threonine protein kinase. Interestingly the stopcodon came from the parental strain B-1A conferring a more efficient fermentation. The resulting protein is truncated for $93 \mathrm{C}$-terminal amino acids but conserves its catalytic domain. This allelic variation was not detected in any other strains $(n=100)$. Thereafter this mutation is named $V H S 1^{B}$ in opposition to the wild type allele $\mathrm{VHSl}^{G}$ carried by the parental strain G-4A and the reference strain S288c. The effect of this gene was partially validated by RHA by constructing the hemizygous hybrids H4-VHS1-G and
H4-VHS1-B (Table 1). In the experimental conditions used for QTL mapping $\left(260 \mathrm{~g} / \mathrm{L}\right.$ of sugar, $\left.28^{\circ} \mathrm{C}\right)$, we did not observe a significant effect of this gene due the very high variability observed within repetitions. However, by reducing the sugar concentration to 240 $\mathrm{g} / \mathrm{L}$ and increasing the fermentation temperature up to $32{ }^{\circ} \mathrm{C}$ a significant effect of the $V H S 1^{B}$ allele was observed (Fig. 6a and b). As for OYE2, no differences are found neither for growth, biomass production, nor viability whatever the culture medium used (synthetic grape juice or laboratory medium). The weak effect observed is likely due to the fact that other genes in this genetic region also impact this phenotype. The hybrid $\mathrm{H} 4$ has the same phenotypic 


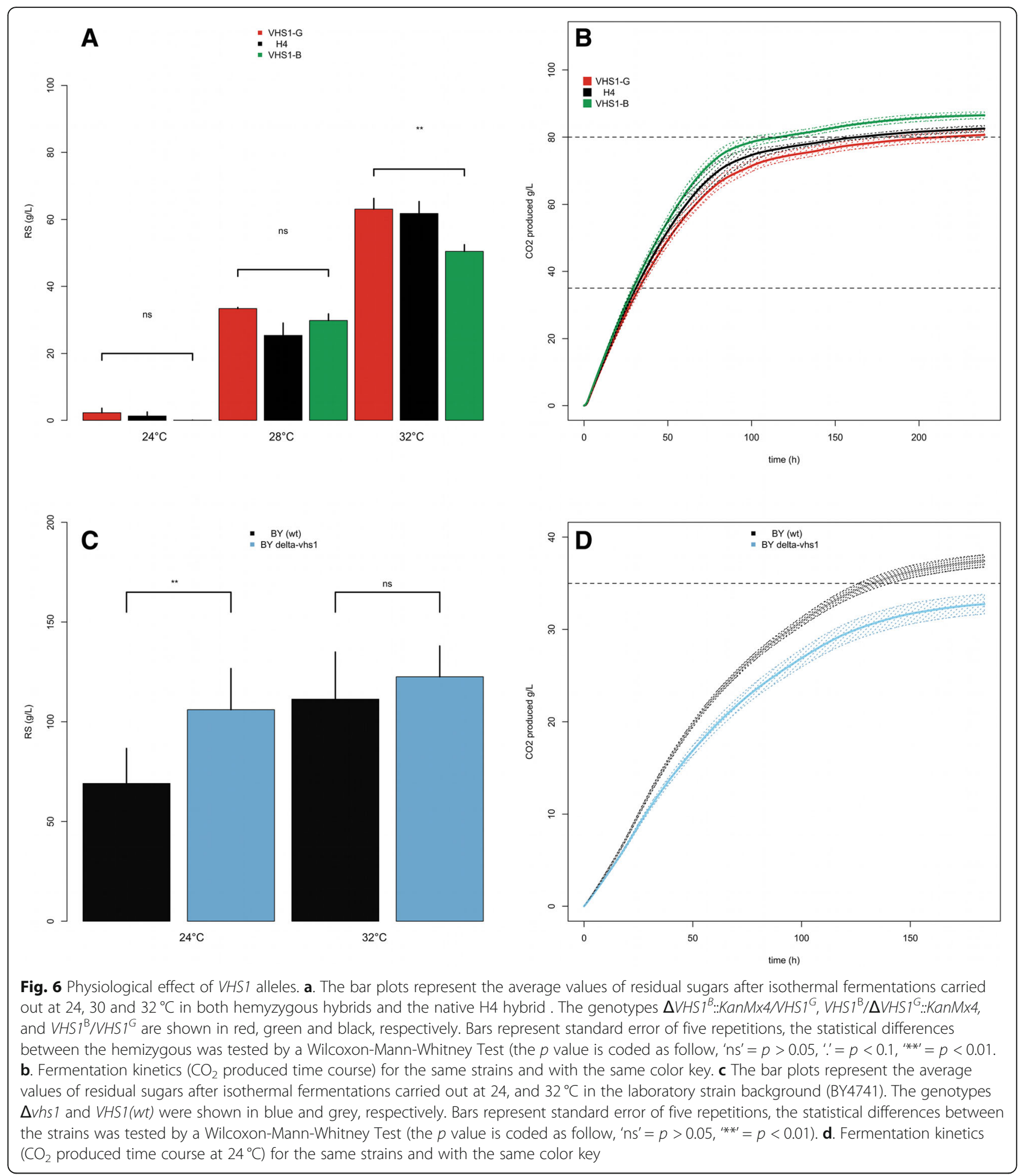

level than the hemizygous hybrid H4-VHS1-G suggesting that the beneficial allele $V H S 1^{B}$ is mostly recessive. Alike for $O Y E 2$, we verified the VHS1 effect in another genetic background (BY4741) applying milder fermentation conditions $(180 \mathrm{~g} / \mathrm{L}$ of sugar). The deletion mutant $\Delta v h s 1$ (Y03606) showed a significative reduction of fermentation efficiency respect to the control by leaving more residual sugars (Fig. 6c) and having a slower fermentation kinetics (Fig. 6d). In contrast to the results observed in the H4 background, the deletion effect of VHS1 was not observed at $28^{\circ} \mathrm{C}$ but only at $24^{\circ} \mathrm{C}$. Again, a very high phenotypic variability within repetition was observed and the 
laboratory strain showed a very sluggish fermentation kinetics consuming only $40 \%$ of the total sugar. This strong variability illustrates the difficulty to asses precisely phenotypes associated to stuck fermentation that could depends on intra-individual phenotypic variability. These additional results also suggest that the complete loss of function of this protein is deleterious for fermentation efficiency. Strikingly, the effect of total deletion of VHS1 in BY background contrasted with the partial C-terminal deletion observed in H4. Indeed, the $V H S 1^{B}$ allele has a positive effect on the fermentation efficiency. Altogether, reciprocal hemizygous and functional genetic analyses of VHS1 in another background provide new insights of this poorly characterized kinase. Interestingly a positive natural allelic variation associated to fermentation resistance in high temperature and ethanol conditions has been identified. The weak effect of this mutation suggested that VHS1 is not the unique gene explaining the effect of this QTL. Therefore, other allelic variations physically linked to VHS1 are likely involved and remain to be identified.

\section{Discussion}

\section{A backcross strategy for mapping quantitative trait loci related to the late fermentation part}

In order to reduce the genotyping cost, the QTL mapping was carried out on a Nearly Isogenic Lineage (NIL). This lineage is derived from meiotic segregants of the hybrid $\mathrm{H} 4$, which has been obtained by successive backcrosses, using as parental donor the strain $\mathrm{B}-1 \mathrm{~A}$, and as recipient one the strain G-4A. Main regions inherited from B-1A were identified by genotyping the seven best segregants of $\mathrm{H} 4$ using Yeast Tiling Microarrays (YTM). This selective genotyping strategy is routinely used in quantitative genetics and allows the reduction of genotyping effort by increasing the detection power of major QTLs [33]. Selective genotyping could be achieved by Bulk Segregant Analysis which requires pooling large set of extreme segregants [36]. In yeast, this strategy has been particularly useful for mapping QTLs linked to fitness differences by allowing an easy selection of numerous individuals with extreme phenotypes [37]. In our experimental conditions, all the progenies showed a similar growth/viability and are mostly different for their fermentation kinetics and their residual sugars values. Therefore, an easy selection based on fitness or viability was not possible and all of them were phenotyped individually. The selection of only seven segregants representing the tail of RS distribution (the best $10 \%$ ) was sufficient to map 12 genomic regions by using Tiling microarray. Once the main introgressed regions have been localized, we applied an additional filter using the parental genome sequences. This filter was necessary since the SNPs detected by
Tiling microarray were not all reliable $(\mathrm{FDR}=65 \%)$. A subset of 43 bi-allelic markers segregating in a Mendelian way across the $\mathrm{H} 4$ population was successfully defined. Those markers were selected in genomic regions mostly inherited from B-1A strain assuming the fact that most of alleles allowing a more efficient fermentation would be brought by this parental strain. By genotyping 77 segregants, 2 main QTLs (VIII_464 and IV_953) were detected confirming the efficiency of our strategy. Despite the low-density map used, it is noteworthy that both QTL mapped are very close (less than $4 \mathrm{~kb}$ ) to the two genes investigated (OYE2 and VHS1). However, this first linkage analysis captured only $40 \%$ of the total phenotypic variation observed. The identification of only two major QTLs is consistent with quantitative genetics theory. In fact, most of the QTL-studies fail to capture all the genetic variability especially due to the strong epistatic relations within QTLs [38]. In order to find out other minor QTLs, the effect of those major loci was removed by achieving another cross among phenotypically distant progenies having the same inheritance (B) for the markers VII_464 and IV_953. This additional analysis leads to map a third locus localized at the end of chromosome XV (peak linkage at the marker XV_1051). Due to the weak effect of this QTL, we did not investigate the causative genes of this region. However, some details recently reported stroke our attention. The end of chromosome XV was linked with the genomic region $\mathrm{C}$ acquired by horizontal transfer which is present by most of the wine yeast [39]. Recently, it was demonstrated that the genes FOT1-2 of this region derived from Torulaspora microellipsoides confers evolutionary advantages in grape must fermentations [40]. However, both parental strains have a full copy of the gene FOT1-2 suggesting that the cause of their phenotypic discrepancy is elsewhere. By comparing the read coverage of the parental strains, we found that $\mathrm{B}-1 \mathrm{~A}$ has a $12-\mathrm{kb}$ deletion in the right subtelomeric part of the chromosome XV (Additional file 9). This deletion encompassed the genes FIT2, FIT3, FRE5, YOR385W, PHR1, and YOR387W and has been previously described for other yeast strains [41]. Since the allele of the strain B-1A confers temperature sensitivity, the lack of one or many genes of this region could be directly involved. Similarly, a recent work linked the cold temperature tolerance with various subtelomeric regions of chromosome XIII, XV, and XVI having such kind of deletion [42]. Our results suggest that the right arm of chromosome XV might play a possible role on fermentation completion in the applied conditions. However, further genetic analyses are obviously necessary for confirming this hypothesis and 
identifying the causative gene(s) involved. Some segregants carrying all the three positive alleles constitute a relevant genetic material for carrying out breeding programs in order to improve the performance of other strains by using marker assisted selection strategies [43].

\section{New insights in the physiological role of the old yellow reductase Oye2p}

We attempted to dissect at the gene level the two major QTL identified. First the locus VIII_464 accounting for more than $25 \%$ of the Residual Sugar variance (Table 5) was investigated. By using a Reciprocal Hemizygosity Analysis, the role of the gene OYE2 (YHL179c) was established. The allele $O Y E 2^{G}$ reduced the efficiency of alcoholic fermentation since the parental strain G-1A has a two nucleotides deletion (c.229_230delTC) which generates a truncated protein of 94 amino acids (instead of the 400 expected). In the G-1A background, this allele conferred the same phenotype than the null mutation oye2::KanMx4 (data not shown). In the industrial background, the $O Y E 2^{G}$ effect is only observed during the alcoholic fermentation of high quantity of sugars when the temperature exceeds $32{ }^{\circ} \mathrm{C}$ (Fig. 5). Similar phenotypes were investigated in another unrelated background (S288c) (Additional file 8). However, in this background, the gene deletion affects fermentation performances whatever the temperature impairing to establish a general link between OYE2 and the temperature resistance. Moreover, our results did not perfectly validate that OYE2 is the unique genetic factor contributing to stuck fermentation at this locus. Indeed, at $28{ }^{\circ} \mathrm{C}$ phenotypic differences within hemizygous hybrids were closer (and poorly significative) than those observed within $\mathrm{H} 4$ progenies having inherited the $\mathrm{G}$ and $\mathrm{B}$ alleles, respectively.

This basic functional characterization of OYE2 deletion supports the idea that its related protein could play a secondary physiological role in drastic fermentation conditions $\left(32^{\circ} \mathrm{C}, 260 \mathrm{~g} / \mathrm{L}\right.$ of sugar). The protein Oye2p is a conserved NADPH oxydoreductase [44] belonging to the large family of flavoenzymes that has a growing interest in biocatalysis [45]. Despite several studies, the physiological role of Oye2p remains unclear. Large-scale functional genomics suggested that Oye2p should have a possible role in cytoskeleton assembly [46] as well as in oxidative stress response $[47,48]$. This mitochondrionassociated protein was also characterized for its antiapoptotic effect by lowering Programed Cell Death (PCD) after various oxidative treatments [48]. Interestingly, a connection between oxidative stress conditions and heat shock has been previously established for this gene [49]. The effect of oye 2 deletion on cell viability after a transient heat shock $\left(50{ }^{\circ} \mathrm{C}, 20 \mathrm{~min}\right)$ was only observed when the cells are sampled during the stationary phase but not during exponential growth [49]. These results are consistent with the effect detected in $\mathrm{H} 4$ background that occurred only at a relatively high temperature $\left(32^{\circ} \mathrm{C}\right)$. Additional characterization efforts a necessary for better understanding the protective role of Oye $2 p$ in such conditions. This might be due to its protective effect against ROS (Reactive Oxygen Species) that are observed in important amount in late steps of wine alcoholic fermentation [50]. Since high temperature [51] and ethanol [52] promote ROS production in S. cerevisiae, the harsh conditions met in our experiment may have emphasized this phenomenon. A possible connection between ROS production and fermentation efficiency would be the potential role of OYE2 to prevent Programmed Cell Death as previously proposed [53]. However, neither the cell viability nor the biomass production is impacted in hemizygous H4-hybrids (Additional file 7, Table 5).

Interestingly, the phenotypic discrepancy observed within $\mathrm{H} 4$ hemyzygous appeared after $67 \mathrm{~h}$ of fermentation when more than $70 \%$ of sugar has been consumed. At this stage the ethanol concentration is higher than $11 \% \mathrm{Vol}$ and becomes very toxic for fermenting yeast. In this context, high temperatures $\left(32^{\circ} \mathrm{C}\right.$ and in a less extent $28^{\circ} \mathrm{C}$ ) act as a strong perturbating factor enhancing the chance to trig stuck fermentations. Since no differences in yeast fitness (viability or concentration) were observed, the OYE2 effect pointed out might be directly or indirectly related to metabolic and/or transport activity of fermenting yeast. This could be due to various perturbations in cellular process that are impacted by the deactivation of this gene, including actin polymerization [54], cellular glutathione content [48], and sterol metabolism [55].

\section{Evidence of a truncated form of the protein Vhs1p impacting fermentation efficiency}

A second QTL (IV_953) linked to stuck fermentation was also partially resolved at the gene level. By comparing the genomic sequence of parental strains, we detected close to the QTL peak (IV_953), a non-sense mutation (c.1116C > A) in the coding sequence of VHS1 of the strain B1-A. Reciprocal hemizygous analysis was carried out in order to demonstrate the effect of gene VHS1. However, conditions applied were not those of the QTL mapping analysis since both hemizygous hybrids failed to ferment at $260 \mathrm{~g} / \mathrm{L}$ of sugar and showed a strong phenotypic variability within repetitions. By decreasing the sugar content (and by consequence ethanol amount) a slight effect was eventually measured in the $\mathrm{H} 4$ background at $32{ }^{\circ} \mathrm{C}$ (Fig. 6). VHS1 encodes a cytoplasmic serine/threonine protein kinase; strikingly, the favorable allele suspected, $V H S 1^{B}$, generates a truncated C-terminal protein of 371 amino acid instead of 461 . 
This 90 amino acids deletion do not encompass the protein kinase domain (PS50011) suggesting that the truncated form might conserve its serine-threonine kinase activity. More over, the positive effect of the truncated allele of $V H S 1^{B}$ contrasted with the full deletion of VHS1 done in the BY background (Fig. $6 \mathrm{c}$ and d). Indeed, in $\mathrm{H} 4$ hemizygous hybrids a significative effect was found only at $32^{\circ} \mathrm{C}$ while, in the laboratory background, the full deletion of VHS1 significantly impact fermentation only at $24^{\circ} \mathrm{C}$.

These contrasted effects could be explained by gene dosage phenomenon. Indeed, the $\mathrm{H} 4$ experiment only one of the two copies of VHS1 is still present in hemizygous, while no functional copy is present in the BY experiment. Interestingly, VHS1 deletion has been reported to generate haploinsufficiency in an alcoholic fermentation context [56]. More generally, other neighbor genes could control this phenotype and would also contribute to the strong effect of this second QTL. Indeed, compare to the locus VIII_464, this genomic region is quite large ( $>400 \mathrm{~kb}$ ) (Table 3 ) and four markers spaced by $25 \mathrm{~kb}$ were positively linked to the phenotype. Previous studies in S. cerevisiae [7, 25] already described these particularly large QTLs, which could be due to the presence of several causative genes brought by both parental strains. This could be the case here since other genes having a close phenotypic relation with temperature (HSP48) or acid $\mathrm{pH}$ (RKR4) resistances are located in the same region. The molecular function of this kinase has been only partially characterized in a recent study [57]. This protein is involved in the regulation of the Snf1p, a central regulator of the carbon metabolism. By phosphorylating the protein Sip $5 p$, Vhs1p indirectly activates the regulator Snf1p. Therefore, Vhs1p might indirectly promotes the fermentation metabolism by activating the Snf1p pathway.

\section{The complex nature of the genetic determinism of stuck fermentation}

By crossing two strains derived from industrial starters we eventually find out genes and natural allelic variations playing a role in stuck fermentation. This multifacetted complex phenotype depends on the combination of many biotic and abiotic factors and is quite difficult to define. Here, we more specifically focused on the combined effect of temperature and ethanol content that are noteworthy factors affecting yeast viability and metabolic activity [4]. Indeed, it is well documented that many thermosensitive mutations confer a permissive phenotype at mild temperature but generate a non-functional protein in warmer conditions [58]. In the industrial background used (H4), the deleterious impact of high sugar and temperature is modulated by the inheritance of non-sense mutations in the VHS1 and OYE2 genes. Indeed, the allelic versions of the parental strain B leads to a more complete fermentation at high temperature (Fig. $5 \mathrm{~b}$ and $6 \mathrm{a}$ ). Strikingly, by testing the deletion effect of those genes in the BY background, the effect of high temperature was not confirmed even if both genes have a significant impact on the fermentation process (Additional file 8 and Fig. $6 \mathrm{c}$ and d). A possible explanation would be the chaotropic role of temperature that may have facilitated stochastic phenomena enhancing the heterogeneity of fermenting population. This explains some difficulties for measuring accurately the residual sugars concentration especially in VHS1 experiment. Altogether these results emphases the low penetrance of genetic factors due to modifier loci that modulate the architecture of complex traits by epistatic [59] and GxE [60] interactions, but also by controlling the probabilistic traits [61] and expression noise [62] in isogenic populations.

\section{Conclusion}

In this study we identified by a QTL mapping approach, two natural allelic variations impacting the fermentation performance of industrial yeast in sugar rich media ( $>250 \mathrm{~g} / \mathrm{L}$ of glucose-fructose). A third locus encompassing the deletion of 6 subtelomeric genes has been also detected. The combination of selective genotyping and the further selection of few markers did not impact the precision of QTL mapping leading to identify loci explaining a part total phenotypic variation. A first functional characterization work was attempted leading to highlight the role of two new proteins Oye2p and Vhs1p involved in the fermentation completion in a high temperature and a high sugar context.

\section{Methods}

\section{Yeast strains and culture conditions}

All the Saccharomyces cerevisiae strains used during this work were listed in (Table 1). All strains were propagated at $30{ }^{\circ} \mathrm{C}$ on YPD medium ( $1 \%$ yeast extract, $1 \%$ peptone, $2 \%$ glucose) solidified with $2 \%$ agar when required. When necessary the antibiotic G418 (Sigma-Aldrich, St Louis, Missouri, USA) was added at a final concentration of $100 \mu \mathrm{g} / \mathrm{ml}$. The construction of the backcross hybrid H4 and the description of the initial parental strains G-4A and B-1A have been previously reported [5]. The hybrid H5 was obtained by crossing two selected meiotic segregants of $\mathrm{H} 4$ ( $\mathrm{H} 4-2 \mathrm{C}$ and $\mathrm{H} 4-19 \mathrm{~B})$ on the basis of their genotype as detailed in result section.

A collection of 77 and 84 meiotic segregants respectively derived from $\mathrm{H} 4$ and $\mathrm{H} 5$ was obtained by spore dissection using a Singer manual apparatus. The segregants obtained are diploid fully homozygous cells due to the homothallic character of the hybrids $\mathrm{H} 4$ and $\mathrm{H} 5$ $(H O / H O)$. Due to their nearly isogenic nature, the 
germination rate of the hybrids $\mathrm{H} 4$ and $\mathrm{H} 5$ were close to $100 \%$ and all the segregants showed the same fitness on laboratory media.

\section{Phenotype measurement Alcoholic fermentation}

Fermentations were run in the KP medium, a synthetic grape juice which mimics a standard grape juice [63]. This medium was sterilized by filtration through a $0.45 \mu \mathrm{m}$ nitrate-cellulose membrane (Millipore, Molsheim, France). Phenotypes were measured in a medium containing 260 g. $\mathrm{L}^{-1}$ of sugars (50\% fructose- $50 \%$ glucose) with a diluted amount of anaerobic growth factors ( $+\mathrm{A}$ - conditions) as described previously [5]. For the fermentation with the BY strains, the amount of sugar was reduced to $160 \mathrm{~g} / \mathrm{L}$. moreover in such experiment the strain auxotrophies were complemented by adding uracil $(20 \mathrm{mg} / \mathrm{L})$, methionine $(20 \mathrm{mg} / \mathrm{L})$, leucine $(30 \mathrm{mg} / \mathrm{L})$, histidine $(30 \mathrm{mg} / \mathrm{L})$ in the synthetic media. A solution stock of [ergosterol $\left(15 \mu \mathrm{g} . \mathrm{L}^{-}\right.$ $\left.{ }^{1}\right)$, sodium oleate $(5 \mu \mathrm{g} / \mathrm{L})$ and $1 \mathrm{~mL}$ Tween $80 /$ ethanol (1: $1, \mathrm{v} / \mathrm{v})]$ was added in the medium with a 5000 fold dilution. Pre-cultures were run in Erlenmeyer flasks for $24 \mathrm{~h}$ at $24{ }^{\circ} \mathrm{C}$ under orbital agitation $(150 \mathrm{rpm})$ in the fermentation media filtered and diluted 1:1 with milli-Q water. The inoculum concentration was $10^{6}$ viable cells per ml. Fermentations were then run in closed $150 \mathrm{~mL}$ glass-reactors, locked to maintain anaerobiosis, with permanent stirring $(300 \mathrm{rpm})$ at $28^{\circ} \mathrm{C}$. The $\mathrm{CO}_{2}$ released was monitored by measurement of glass-reactor weight loss regularly and expressed in g. $\mathrm{L}^{-1}$. Raw weight lost data were smoothed by a Loess function allowing the estimation of various kinetics parameters. The CO2max (g. $\mathrm{L}^{-1}$ ) was the maximal amount of $\mathrm{CO}_{2}$ produced during the fermentation, the $L P$ (h) was the lag phase time before the $\mathrm{CO}_{2}$ production rate was higher than $0.05 \mathrm{~g} . \mathrm{L}^{-1} \cdot \mathrm{h}^{-1}$, the T35, T50, T70 are the time necessary to reach 35,50 and $70 \%$ of the maximal amount of $\mathrm{CO}_{2}$ expected (125 g.L. $\mathrm{L}^{-1}$ ); the rate $50-70$ (g. $\mathrm{L}^{-}$ ${ }^{1} \cdot \mathrm{h}^{-1}$ ) was the rate of $\mathrm{CO} 2$ released between $T 70$ and $T 50$. Due to the important number of progenies analyzed, two distinct batches of fermentation were carried out. To estimate eventual block effects parental strains (G-4A, B-1A for H4) and (H4-2C, H4-19B for H5) were fermented in both batches two (or three) times leading to get 4 (or 5) replicates of each parent and their relative hybrids. No significative block effects were observed for the traits analyzed (data not shown). For the H4 segregants, all the fermentations were done in duplicate, for the H5 segregants only one series was carried out.

\section{Fermentation analyses}

At the end of the alcoholic fermentation, the synthetic wines were analyzed for basic enological parameters. Glucose and Fructose consumed were estimated by enzymatic assay using the kit $\mathrm{n}^{\circ} 10139106035$ according to manufacturer protocol (R-Biopharm, Germany) and the $R S$ (Residual Sugars) was computed as the sum of remaining glucose and fructose (expressed in g.. ${ }^{-1}$ ). The linearity of this method was presented in the Additional file 10 and was recently published [64]. Ethanol $(\% \mathrm{Vol})$ was measured by infrared reflectance using an Infra-Analyzer 450 (Technicon, Plaisir, France).

\section{Whole genome sequencing of parental strains}

Whole genome sequences of strains B-1A and G-4A were obtained by using Illumina pair-end sequencing. Briefly, genomic DNA was extracted from a saturated culture of $100 \mathrm{ml}$ under anaerobic condition (YPD) using the genomic tip-100 kit (Qiagen, Courtaboeuf, FRANCE). Pairedend Illumina sequencing libraries were prepared from sonicated genomic DNA according to manufacturer protocols (Genomic DNA Sample Preparation) and were realized by the Genomic and Transcriptomic Facility of Bordeaux, FRANCE. Sequencing was performed on Illumina Genome Analyzer IIx (Illumina, Palo Alto, CA) with a read length of $54 \mathrm{bp}$. Raw reads data have been deposited in the SRA at NCBI with the accession number PRJNA419624. The genome coverage was respectively 45X and 34X for B-1A and G-4A, respectively. After reads quality trimming and filtration step, each strain was aligned to the reference genome of Saccharomyces cerevisiae S288c (version Apr2011/sacCer3) using "Bowtie2" with default parameters. Single Nucleotide Polymorphisms (SNPs) were called using Samtools mpileup with mapping quality $\geq 30$, base quality $\geq 20$, and varFilter depth $\geq 10$. Single amino-acid polymorphisms were identified using snpEff [65] requiring quality QUAL $\geq 30$ and genotype GEN[*] GQ $\geq 20$. Using this procedure, we defined a set of 9829 high-quality SNP ( $\mathrm{Q}>30$, homozygous) named WGS-SNP and given in (Additional file 4).

\section{Selective genotyping using yeast tiling microarrays (YTM)} The genomic DNA of the diploid parental strains (G-4A, B-1A) and of seven H4 segregants was isolated as previously described [31] and hybridized onto GeneChip S. cerevisiae Tiling Array 1.0 from Affymetrix (Palo Alto, CA) following the protocol detailed by Gresham et al. [32]. Hybridization and microarray scanning were performed by the ProfileXpert platform (Lyon, France). For each parental strain, two independent hybridizations were carried out. Single Nucleotide Polymorphism (SNP) and short Insertion Deletion (INDEL) were searched using the SNPscanner program [32] built for scanning SNP on the reference genome release R49-1-1 (2005). In order to reduce the heterogeneity of fluorescence signal between each microarray, the $\mathrm{Z}$ score of hybridization signal was calculated according to [66]. The prediction threshold of $\mathrm{z}$ scored-transformed data was higher than 2.5 and only regions extending for at 
least 10 nucleotides above the signal threshold were conserved. This approach allows recovering 3354 putative markers within the strains. Using the same procedure, seven segregants of the hybrid $\mathrm{H} 4$ were genotyped. The compiled set of YTM markers inherited from B-1A and G-4A found in the seven segregants was listed in the (Additional file 3). The Perl and $R$ scripts used for computing these dataset are available on request.

\section{PCR-based KASP ${ }^{\text {TM }}$ genotyping of $\mathrm{H} 4$ and $\mathrm{H} 5$ progenies}

Genomic DNA of segregants were extracted using the Genome Wizard (Promega, France) kit using the modified conditions described by Zimmer et al. [35]. The inheritance of 43 SNP was investigated using the KASP genotyping assay based on the use of one universal FRET cassette reporter system. Primers design and genotyping were performed by LGC genomics (Hertz, UK).

\section{Reciprocal hemizygosity assay}

Gene deletion were carried out by homologous recombination using deletion cassette constructed by PCR using as template the genomic DNA of Euroscarf collection strains (Euroscarf, Franckfurt, Germany). The OYE2 and VHS1 deletion cassette were obtained using as template the genomic DNA of the strains Y02873 and Y03606, respectively. All the constructs were verified by both insertion and deletion PCR test. The insertion test consists to positively amplify by PCR a fragment containing the $5^{\prime}$ part of the KanMx4 cassette and $\sim 600 \mathrm{bp}$ of the $5^{\prime}$-flanking region of the target gene. Deletion test consists in the absence of amplification of a central portion of the target gene. The hybrid $\mathrm{H} 4$ and the parental strains B-1A and G-4A were transformed using the lithium acetate protocol described by Gietz and Schiestl [49]. The allele identity in hemizygous hybrids was tested by sequencing. All the primers used are listed in Additional file 11. For each hemizygous hybrid assay at least two independent clones of each genotype were tested.

\section{Determination of cell viability and concentration}

The cell concentration (cells $/ \mathrm{ml}$ ) as well the cell viability were estimated at $70 \%$ of the total $\mathrm{CO}_{2}$ expected using a flow cytometer (Quanta SC MPL, Beckman Coulter, Fullerton, California), equipped with a $488 \mathrm{~nm}$ laser $(22 \mathrm{~mW})$ and a $670 \mathrm{~nm}$ long-pass filter. Samples were diluted in McIlvaine buffer $\mathrm{pH}=4.0(0.1 \mathrm{M}$ citric acid, $0.2 \mathrm{M}$ sodium phosphate dibasic) added with propidium iodide $(0.3 \% \mathrm{v} / \mathrm{v})$ in order to stain dead cells (FL3 channel).

\section{Graphical and statistical analyses}

All the statistical and graphical analyses were carried out using the $\mathrm{R}$ program ( $\mathrm{R}$ version 3.3.3 2017-03-06). The custom $\mathrm{R}$ scripts used are available on request. The global heritability of each trait $\left(\mathrm{h}^{2}\right)$ was estimated as described previously [63]. The correlation among traits were estimated using a Pearson test corrected by a Bonferroni's test using the $\mathrm{R}$ package Coortest. Linkage analysis was carried out according to the non-parametric method (Wilcoxon-Mann-Whitney) used by Zimmer et al. [35]; and by calculating for each trait a significant threshold by 1000 permutation tests $(\alpha=0.05)$. The QTLs, genes, and temperature effects were estimated by standard complete linear models (with interaction) and further analyzed by ANOVA (type II). For each variable, the homogeneity of the variance was assessed using a Levene test (car package) and the normality of residual distribution was controlled using a Shapiro test $(\alpha>0.01)$. Duncan's multiple comparison was used to determine which means differ significantly (Duncan's multiple comparison, $\alpha=0.05)$ using the agricolae package. When required, pairwise comparisons were carried out using the Wilcoxon test with at least four independent repetitions.

\section{Additional files}

Additional file 1: Fermentation kinetics of the 77 segregants and the two parental strains G-4A (red) and B-1A (green). (TIFF 2437 kb)

Additional file 2: Trait distribution among $\mathrm{H} 4$ progeny. The green, red and black full dots represent the parental values of the strains B-1A, G-4A and H4. (TIFF $21796 \mathrm{~kb}$ )

Additional file 3: Correlation analysis within each trait investigated in the $\mathrm{H} 4$ progeny. The test applied was the Pearson test. The size and the color of the dots represent the pvalue and the correlation rate, respectively. Only significant correlations corrected $p$ values $(\mathrm{BH})$ lower than 0.001 were shown. (TIFF $21796 \mathrm{~kb}$ )

Additional file 4: SNP detected by NGS (sheet 1); Tiling (Sheet 2) and filtered markers with their occurrence in the 7 segregants genotyped (sheet 3) (XLSX 544 kb)

Additional file 5: KASP Markers used for linkage analysis (XLSX 12 kb) Additional file 6: List on SNP within parental strains and their effect for loci on chromosomes VIII and IV (XLSX $10 \mathrm{~kb}$ )

Additional file 7: Biomass viability for the hemyzygous hybrids

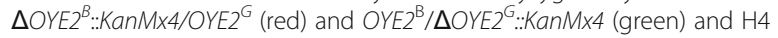
(black). The dots represent mean value for the sampling points and the shaded area the standard deviation estimated with at least five repetitions. (TIFF $1720 \mathrm{~kb}$ )

Additional file 8: Panel A. The bar plots represent the average values of residual sugars after isothermal fermentations carried out at 24 , and $32{ }^{\circ} \mathrm{C}$ in the laboratory strain background (BY4741). The genotypes $\Delta$ oye2 and OYE2(wt) were shown in blue and grey, respectively. Bars represent standard error of five repetitions, the statistical differences between the hemizygous was tested by a Wilcoxon-Mann-Whitney Test (the $p$ value is coded as follow, $\left.{ }^{\prime * \prime}=p<0.05\right)$. Panel B. Fermentation kinetics $\left(\mathrm{CO}_{2}\right.$ produced time course at $24^{\circ} \mathrm{C}$.) for the same strains and with the same color key (TIFF $9490 \mathrm{~kb}$ )

Additional file 9: This figure illustrates the deletion observed in the strain B-1A for the genomic region encompassing the genes FIT2, FIT3, FRE5, YOR385W, PHR1, YOR387C. The deletion was found by comparing the read per $\mathrm{kb}$ observed for all the genes of the right arm of chromosome XV. Green bars (B-1A), red bars (G-4A). (TIFF $1480 \mathrm{~kb}$ )

Additional file 10: Reliability of the enzymatic assay of glucose and fructosePanel A. Linearity of the assay. The values shown are the average 
of two repetitions and the error bar indicates the standard deviation. The blue line indicates the linear regression line, the adjusted R-Squared is indicated. Panel B. Recovery of the assay. Each point represents the average value of three repetitions. The error bars indicate the standard deviation. The blue line indicates the linear regression line. Recovery is indicated. Linearity of the assay (panel A). The concentration of a sample was measured at different dilution levels (1/100, 1/200 and 1/400). Linear regression with a R-Squared close to 1 indicates the linearity of the enzyme assay in this range $(0.15 \mathrm{~g} / \mathrm{L}-0.6 \mathrm{~g} / \mathrm{L})$. Recovery of the assay (panel B). Different concentrations of glucose or fructose are added to a sample $(0.4 \mathrm{~g} / \mathrm{L}, 1 \mathrm{~g} / \mathrm{L}, 10 \mathrm{~g} / \mathrm{L}$ and $15 \mathrm{~g} / \mathrm{L})$. The slope of the linear regression line indicates which part of the added concentration is actually measured (recovery). A slope close to 1 shows a good recovery of the assay between $0.4 \mathrm{~g} / \mathrm{l}$ and $15 \mathrm{~g} / \mathrm{l}$. (PDF $75 \mathrm{~kb}$ )

Additional file 11: Details of the gene deletion method. (DOCX $65 \mathrm{~kb}$ )

\section{Abbreviations}

INDEL: Insertion DELetion; NIL: Nearly Isogenic Line; PCD: Programmed Cell Death; QTL: Quantitative Trait Loci; RHA: Reciprocal Hemizygous Assay; ROS: Reactive Oxygen species; SNP: Single Nucleotide Polymorphism

\section{Acknowledgements}

Not applicable.

\section{Authors' contributions}

PM and DD conceived the work, PM, EP, PD, MB and CM realized experiments, PM wrote the manuscript. All authors read and approved the final manuscript.

\section{Funding}

PM received 2 grants from Conseil Regional d'Aquitaine (SAGESSE for genome sequencing, and QTL2 for genotyping). The funders had no role in study design, data collection and analysis, decision to publish, or preparation of the manuscript.

\section{Availability of data and materials}

The datasets supporting the conclusions of this article are included within the article (5 tables, 6 figures) and its 11 additional files.

\section{Ethics approval and consent to participate}

Not applicable.

\section{Consent for publication}

Not applicable.

\section{Competing interests}

MB, CM, EP and PM are employed by BIOLAFFORT company. This does not alter the authors' adherence to all the journal policies on sharing data and materials.

\section{Author details}

'University of Bordeaux, ISW, Unité de recherche OEnologie EA 4577, USC 1366 INRA, 33140 Bordeaux INP, Villenave d'Ornon, France. ${ }^{2}$ Biolaffort, 33100 Bordeaux, France. ${ }^{3}$ CNRS UMR 5800, University of Bordeaux, 33405 Talence, France. ${ }^{4}$ Inria Bordeaux Sud-Ouest, Joint team Pleiade Inria/INRA/CNRS, 33405 Talence, France.

Received: 6 March 2018 Accepted: 4 July 2019

Published online: 28 August 2019

\section{References}

1. Peter J, De Chiara M, Friedrich A, Yue J-X, Pflieger D, Bergström A, Sigwalt A, Barre B, Freel K, Llored A, Cruaud C, Labadie K, Aury J-M, Istace B, Lebrigand K, Barbry P, Engelen S, Lemainque A, Wincker P, Liti G, Schacherer J. Genome evolution across 1,011 Saccharomyces cerevisiae isolates. Nature. 2018,556:339-44

2. Sicard D, Legras JL. Bread, beer and wine: yeast domestication in the Saccharomyces sensu stricto complex. Comptes Rendus - Biol. 2011;334:229-36.

3. Zhao XQ, Bai FW. Mechanisms of yeast stress tolerance and its manipulation for efficient fuel ethanol production. J Biotechnol. 2009;144:23-30.
4. Bisson LF. Stuck and sluggish fermentations. Am J Enol Vitic. 1999;50:107-19.

5. Marullo P, Mansour C, Dufour M, Albertin W, Sicard D, Bely M, Dubourdieu D. Genetic improvement of thermo-tolerance in wine Saccharomyces cerevisiae strains by a backcross approach. FEMS Yeast Res. 2009:9:1148-60.

6. Mitsumasu K, Liu Z-S, Tang Y-Q, Akamatsu T, Taguchi H, Kida K. Development of industrial yeast strain with improved acid-and thermo-tolerance through evolution under continuous fermentation conditions followed by haploidization and mating. J Biosci Bioeng. 2014;118:689-95.

7. Martí-Raga M, Peltier E, Mas A, Beltran G, Marullo P. Genetic Causes of Phenotypic Adaptation to the Second Fermentation of Sparkling Wines in Saccharomyces cerevisiae. G3 Genes Genomes Genet. 2017;7:399-412.

8. Hasunuma T, Sanda T, Yamada R, Yoshimura K, Ishii J, Kondo A. Metabolic pathway engineering based on metabolomics confers acetic and formic acid tolerance to a recombinant xylose-fermenting strain of Saccharomyces cerevisiae. Microb Cell Factories. 2011:10:2

9. Taherzadeh M, Gustafsson L, Niklasson C. Physiological effects of 5hydroxymethylfurfural on Saccharomyces cerevisiae. Appl Microbiol. 2000; 53:701. https://doi.org/10.1007/s002530000328.

10. Blateyron L, Sablayrolles JM. Stuck and slow fermentations in enology: statistical study of causes and effectiveness of combined additions of oxygen and diammonium phosphate. J Biosci Bioeng. 2001;91:184-9.

11. Rich JO, Leathers TD, Bischoff KM, Anderson AM, Nunnally MS. Biofilm formation and ethanol inhibition by bacterial contaminants of biofuel fermentation. Bioresour Technol. 2015;196:347-54.

12. Jarosz DF, Brown JCS, Walker GA, Datta MS, Ung WL, Lancaster AK, Rotem A Chang A, Newby GA, Weitz DA, Bisson LF, Lindquist S. Cross-kingdom chemical communication drives a heritable, mutually beneficial prion-based transformation of metabolism. Cell. 2014;158:1083-93.

13. Aldiguier AS, Alfenore S, Cameleyre X, Goma G, Uribelarrea JL, Guillouet SE, Molina-Jouve C. Synergistic temperature and ethanol effect on Saccharomyces cerevisiae dynamic behaviour in ethanol bio-fuel production. Bioprocess Biosyst Eng. 2004;26:217-22.

14. Choudhary J, Singh S, Nain L. Thermotolerant fermenting yeasts for simultaneous saccharification fermentation of lignocellulosic biomass. Electron J Biotechnol. 2016;21:82-92.

15. Olofsson $K$, Bertilsson $M$, Lidén $G$, Saidi B, Braun $R$, Jönsson L, Saez F, Saez R, Wegner T, Zerbe J. A short review on SSF ? An interesting process option for ethanol production from lignocellulosic feedstocks. Biotechnol Biofuels. 2008;1:7.

16. Colombié S, Malherbe S, Sablayrolles JM. Modeling of heat transfer in tanks during wine-making fermentation. Food Control. 2007;18:953-60.

17. Guymon JF, Crowell EA. The nature and cause of cap-liquid temperature differences during wine fermentation. Am J Enol Vitic. 1977;28:74-8.

18. Cha Y-L, An GH, Yang J, Moon Y-H, Yu G-D, Ahn J-W. Bioethanol production from Miscanthus using thermotolerant Saccharomyces cerevisiae mbc 2 isolated from the respiration-deficient mutants. Renew Energy. 2015:80:259-65.

19. Shi D, Wang C, Wang K. Genome shuffling to improve thermotolerance, ethanol tolerance and ethanol productivity of Saccharomyces cerevisiae. J Ind Microbiol Biotechnol. 2009;36:139-47.

20. Caspeta L, Chen Y, Ghiaci P, Feizi A, Buskov S, Hallström BM, Petranovic D, Nielsen J. Biofuels. Altered sterol composition renders yeast thermotolerant. Science. 2014:346:75-8.

21. Çakar ZP, Seker UOS, Tamerler C, Sonderegger M, Sauer U. Evolutionary engineering of multiple-stress resistant Saccharomyces cerevisiae. FEMS Yeast Res. 2005;5:569-78.

22. McCusker JH, Clemons KV, Stevens DA, Davis RW. Genetic characterization of pathogenic Saccharomyces cerevisiae isolates. Genetics. 1994;136:1261-9.

23. Auesukaree C, Koedrith P, Saenpayavai P, Asvarak T, Benjaphokee S, Sugiyama M, Kaneko Y, Harashima S, Boonchird C. Characterization and gene expression profiles of thermotolerant Saccharomyces cerevisiae isolates from Thai fruits. J Biosci Bioeng. 2012;114:144-9.

24. Vianna CR, Silva CLC, Neves MJ, Rosa CA. Saccharomyces cerevisiae strains from traditional fermentations of Brazilian cacha?A: trehalose metabolism, heat and ethanol resistance. Antonie Van Leeuwenhoek. 2008:93:205-17.

25. Steinmetz LM, Sinha H, Richards DR, Spiegelman Jl, Oefner PJ, McCusker JH, Davis RW. Dissecting the architecture of a quantitative trait locus in yeast. Nature. 2002;416:326-30

26. Sinha H, Nicholson BP, Steinmetz LM, McCusker JH. Complex genetic interactions in a quantitative trait locus. PLoS Genet. 2006;2:140-7. 
27. Sinha H, David L, Pascon RC, Clauder-Münster S, Krishnakumar S, Nguyen M, Shi G, Dean J, Davis RW, Oefner PJ, McCusker JH, Steinmetz LM. Sequential elimination of major-effect contributors identifies additional quantitative trait loci conditioning high-temperature growth in yeast. Genetics. 2008;180:1661-70.

28. Yang Y, Foulquié-Moreno MR, Clement L, Erdei E, Tanghe A, Schaerlaekens K, Dumortier FF, Thevelein JM, Foulquié-Moreno MR, Clement L, Erdei É, Tanghe A, Schaerlaekens K, Dumortier FF, Thevelein JM. QTL Analysis of High Thermotolerance with Superior and Downgraded Parental Yeast Strains Reveals New Minor QTLs and Converges on Novel Causative Alleles Involved in RNA Processing. PLoS Genet. 2013;9:e1003693.

29. Parts L, Cubillos FA, Warringer J, Jain K, Salinas F, Bumpstead SJ, Molin M, Zia A, Simpson JT, Quail MA, Moses A, Louis EJ, Durbin R, Liti G. Revealing the genetic structure of a trait by sequencing a population under selection. Genome Res. 2011;21:1131-8.

30. Ribéreau-Gayon P, Dubourdieu D, Donèche B, Lonvaud A. Handbook of Enology, Vol. 1: The Microbiology of wine and vinifications. 2nd ed. Paris: Wiley; 2006. https://doi.org/10.1002/0470010363.

31. Marullo P, Aigle M, Bely M, Masneuf-Pomarède I, Durrens $P$, Dubourdieu D, Yvert G. Single QTL mapping and nucleotide-level resolution of a physiologic trait in wine Saccharomyces cerevisiae strains. FEMS Yeast Res. 2007;7:941-52.

32. Gresham D, Ruderfer DM, Pratt SC, Schacherer J, Dunham MJ, Botstein D, Kruglyak L. Genome-wide detection of polymorphisms at nucleotide resolution with a single DNA microarray. Science. 2006;311:1932-6.

33. Lander ES, Botstein S. Mapping mendelian factors underlying quantitative traits using RFLP linkage maps. Genetics. 1989;121:185.

34. Semagn K, Babu R, Hearne S, Olsen M. Single nucleotide polymorphism genotyping using Kompetitive allele specific PCR (KASP): overview of the technology and its application in crop improvement. Mol Breed. 2014;33:1-14.

35. Zimmer A, Durand C, Loira N, Durrens P, Sherman DJ, Marullo P. QTL dissection of lag phase in wine fermentation reveals a new translocation responsible for Saccharomyces cerevisiae adaptation to sulfite. PLoS One. 2014;9:37-9.

36. Magwene PM, Willis JH, Kelly JK. The statistics of bulk Segregant analysis using next generation sequencing. PLoS Comput Biol. 2011;7:e1002255.

37. Wilkening S, Lin G, Fritsch ES, Tekkedil MM, Anders S, Kuehn R, Nguyen M, Aiyar RS, Proctor M, Sakhanenko NA, Galas DJ, Gagneur J, Deutschbauer A, Steinmetz LM. An evaluation of high-throughput approaches to QTL mapping in Saccharomyces cerevisiae. Genetics. 2014;196:853-65.

38. Bloom JS, Ehrenreich IM, Loo WT, Lite T-LV, Kruglyak L. Finding the sources of missing heritability in a yeast cross. Nature. 2013;494:234-7.

39. Novo M, Bigey F, Beyne E, Galeote V, Gavory F, Mallet S, Cambon B, Legras $J$-L, Wincker P, Casaregola S, Dequin S. Eukaryote-to-eukaryote gene transfer events revealed by the genome sequence of the wine yeast Saccharomyces cerevisiae EC1118. Proc Natl Acad Sci. 2009;106:16333-8.

40. Marsit S, Mena A, Bigey F, Sauvage F-X, Couloux A, Guy J, Legras J-L, Barrio E, Dequin S, Galeote V. Evolutionary advantage conferred by an eukaryote-to-eukaryote gene transfer event in wine yeasts. Mol Biol Evol. 2015;32(7):1695-707.

41. Schacherer J, Shapiro JA, Ruderfer DM, Kruglyak L. Comprehensive polymorphism survey elucidates population structure of Saccharomyces cerevisiae. Nature. 2009;458:342-5.

42. García-Ríos E, Morard M, Parts L, Liti G, Guillamón JM. The genetic architecture of low-temperature adaptation in the wine yeast Saccharomyces cerevisiae. BMC Genomics. 2017;18:159.

43. Marullo P, Yvert G, Bely M, Aigle M, Dubourdieu D. Efficient use of DNA molecular markers to construct industrial yeast strains. FEMS Yeast Res. 2007;7:1295-306

44. Stott K, Saito K, Thiele DJ, Massey V. Old Yellow Enzyme. The discovery of multiple isozymes and a family of related proteins. J Biol Chem. 1993;268:6097-106.

45. Bruce NC, Williams RE. 'New uses for an old enzyme' - the old yellow enzyme family of flavoenzymes. Microbiology. 2002;148:1607-14.

46. Amberg DC, Basart E, Botstein D. Defining protein interactions with yeast actin in vivo. Nat Struct Biol. 1995;2:28-35.

47. Trotter EW, Collinson EJ, Dawes IW, Grant CM. Old yellow enzymes protect against acrolein toxicity in the yeast Saccharomyces cerevisiae. Appl Environ Microbiol. 2006;72:4885-92.

48. Odat O, Matta S, Khalil H, Kampranis SC, Pfau R, Tsichlis PN, Makris AM. Old yellow enzymes, highly homologous FMN oxidoreductases with modulating roles in oxidative stress and programmed cell death in yeast. J Biol Chem. 2007;282:36010-23.
49. Jarolim S, Ayer A, Pillay B, Gee AC, Phrakaysone A, Perrone GG, Breitenbach M, Dawes IW. Saccharomyces cerevisiae genes involved in survival of heat shock. G3 Genes Genomes Genet. 2013;3:2321-33.

50. Landolfo S, Politi H, Angelozzi D, Mannazzu I. ROS accumulation and oxidative damage to cell structures in Saccharomyces cerevisiae wine strains during fermentation of high-sugar-containing medium. Biochim Biophys Acta - Gen Subj. 1780;2008:892-8.

51. Zhang M, Shi J, Jiang L. Modulation of mitochondrial membrane integrity and ROS formation by high temperature in Saccharomyces cerevisiae. Electron J Biotechnol. 2015;18:202-9.

52. Pérez-Gallardo R V, Briones LS, Díaz-Pérez AL, Gutiérrez S, Rodriguez-Zavala JS, Campos-García J, Chavez I: Reactive oxygen species production induced by ethanol in Saccharomyces cerevisiae increases because of a dysfunctional mitochondrial iron-sulfur cluster assembly system. FEMS Yeast Res. 2013; 13(8):804-19. https://doi.org/10.1111/1567-1364.12090. Epub 2013 Oct 7

53. Perrone GG, Tan S-X, Dawes IW. Reactive oxygen species and yeast apoptosis. Biochim Biophys Acta - Mol Cell Res. 2008;1783:1354-68.

54. Farah ME, Amberg DC. Conserved actin cysteine residues are oxidative stress sensors that can regulate cell death in yeast. Mol Biol Cell. 2007;18:1359-65.

55. Higgins VJ, Beckhouse AG, Oliver AD, Rogers PJ, Dawes IW. Yeast genome-wide expression analysis identifies a strong ergosterol and oxidative stress response during the initial stages of an industrial lager fermentation. Appl Environ Microbiol. 2003;69:4777-87.

56. Novo M, Mangado A, Quirós M, Morales P, Salvadó Z, Gonzalez R. Genome-wide study of the adaptation of Saccharomyces cerevisiae to the early stages of wine fermentation. PLoS One. 2013;8:e74086.

57. Simpson-Lavy K, Xu T, Johnston M, Kupiec M. The Std1 Activator of the Snf1/AMPK Kinase Controls Glucose Response in Yeast by a Regulated Protein Aggregation. Mol Cell. 2017;68:1120-1133.e3.

58. Ben-Aroya S, Pan X, Boeke JD, Hieter P. Making temperature-sensitive mutants. Methods Enzymol. 2010;470:181-204.

59. Bloom JS, Kotenko I, Sadhu MJ, Treusch S, Albert FW, Kruglyak L. Genetic interactions contribute less than additive effects to quantitative trait variation in yeast. Nat Commun. 2015;6:8712.

60. Peltier E, Sharma V, Marti Raga M, Roncoroni M, Bernard M, Jiranek V, Gibon $Y$, Marullo P. Genetic basis of genetic x environment interaction in an enological context. BMC Genomics. 2018;19(1):772. https://doi.org/10.1186/ s12864-018-5145-4.

61. Chuffart F, Richard M, Jost D, Burny C, Duplus-Bottin H, Ohya Y, Yvert G. Exploiting single-cell quantitative data to map genetic variants having probabilistic effects. PLoS Genet. 2016;12:e1006213.

62. Ansel J, Bottin H, Rodriguez-Beltran C, Damon C, Nagarajan M, Fehrmann S, Francois J, Yvert G. Cell-to-cell stochastic variation in gene expression is a complex genetic trait. PLoS Genet. 2008;4:e1000049.

63. Marullo P, Bely M, Masneuf-Pomarède I, Pons M, Aigle M, Dubourdieu D, Masneuf-Pomarede I, Pons M, Aigle M, Dubourdieu D. Breeding strategies for combining fermentative qualities and reducing off-flavor production in a wine yeast model. FEMS Yeast Res. 2006;6:268-79.

64. Peltier E, Bernard M, Trujillo M, Prodhomme DD, Barbe J-C, Gibon Y, Marullo $P$. Wine yeast phenomics: a standardized fermentation method for assessing quantitative traits of Saccharomyces cerevisiae strains in enological conditions. PLoS One. 2018:13:191353.

65. Cingolani P, Platts A, Wang LL, Coon M, Nguyen T, Wang L, Land SJ, Lu X, Ruden DM. A program for annotating and predicting the effects of single nucleotide polymorphisms, SnpEff. Fly (Austin). 2012;6:80-92.

66. Cheadle C, Vawter MP, Freed WJ, Becker KG. Analysis of microarray data using Z score transformation. J Mol Diagnostics. 2003;5:73-81.

\section{Publisher's Note}

Springer Nature remains neutral with regard to jurisdictional claims in published maps and institutional affiliations. 